\title{
Street canyon ventilation and airborne pollution dispersion: 2-D versus 3-D CFD simulations
}

Article

Accepted Version

Creative Commons: Attribution-Noncommercial-No Derivative Works 4.0

Mei, S.-J., Luo, Z., Zhao, F.-Y. and Wang, H.-Q. (2019) Street canyon ventilation and airborne pollution dispersion: 2-D versus 3-D CFD simulations. Sustainable Cities and Society, 50. 101700. ISSN 2210-6707 doi:

https://doi.org/10.1016/j.scs.2019.101700 Available at https://centaur.reading.ac.uk/84719/

It is advisable to refer to the publisher's version if you intend to cite from the work. See Guidance on citing.

To link to this article DOI: http://dx.doi.org/10.1016/j.scs.2019.101700

Publisher: Elsevier

All outputs in CentAUR are protected by Intellectual Property Rights law, including copyright law. Copyright and IPR is retained by the creators or other copyright holders. Terms and conditions for use of this material are defined in the End User Agreement.

www.reading.ac.uk/centaur 
Central Archive at the University of Reading

Reading's research outputs online 
1 Manuscript revised for Sustainable Cities and Society, 2019

2

3 Street canyon ventilation and air pollution dispersion: 2-D versus 3-D CFD

4 simulations

5

6 Shuo-Jun Mei ${ }^{\mathrm{abc}}$, Zhiwen Luo ${ }^{\mathrm{c}^{*}}$, Fu-Yun Zhao ${ }^{\mathrm{ab} *}$ Han-Qing Wang ${ }^{\mathrm{d}}$

7 (a) School of Power and Mechanical Engineering, Wuhan University, Wuhan, Hubei Province,

8 China

9 (b) Shenzhen Research Institute, Wuhan University, Shenzhen, Guangdong Province, China

10 (c) School of the Built Environment, University of Reading, Reading, United Kingdom

11 (d) School of Civil Engineering, University of South China, Hengyang, Hunan Province, China

12

$13 *$ Corresponding author:

14 (1) Dr Zhiwen Luo, School of the Built Environment, University of Reading, United Kingdom;

15 E-mail: z.luo@ reading.ac.uk

16 (2) Prof. Fu-Yun Zhao, School of Power and Mechanical Engineering, Wuhan University,

17 Wuhan, Hubei Province, China; E-mail: fyzhao@whu.edu.cn

18

19

20

21

22

23

24

25

26

27 


\section{Abstract}

Urban ventilation is important for building a healthy urban living environment. 2-D CFD simulation has been used widely for street canyon ventilation due to its computational efficiency, but its applicability for a 3-D simulation has never been studied. This paper tried to answer the question: if and under what conditions, the widely-adopted 2-D CFD simulations on street canyon ventilation can represent real 3-D scenarios? 3-D simulations on street canyons with various street lengths and corresponding 2-D simulations are carried out with RNG $k-\varepsilon$ model. Our study identified two important ventilation mechanism for controlling ventilation and dispersion in a 3-D street canyon, i.e., canyon vortex on the canyon top and the corner vortices at the street ends. The relative importance of these two driving forces will change with the street length/street width ratio $(B / W)$. For isolated street canyon, when $B / W$ is higher than 20 (for $H / W=1$ ) and 70 $(H / W=2)$, the street canyon ventilation will be dominated by canyon vortex, and 3-D street canyon ventilation could be simplified as a 2-D case. For multiple street canyon, the threshold of $B / W$ will become 20 when $H / W=1$, and 50 when $H / W=2$. The findings in this study could improve our approaches for simulating urban ventilation.

\section{Keywords}

45 CFD, Corner vortices, Street canyon, Urban ventilation

\section{Introduction}

A 'street canyon' refers to a narrow space between buildings that line up continuously along both sides of a street (Li et al., 2006). It has a unique climate where micro-scale

49 meteorological processes dominate (Oke, 1988). Pollutants emitted at the ground level

50 considerably deteriorate the local air quality and impose direct impacts on human health.

51 The highest level of pollution and the most outdoor human activities are both concentrated at street canyons, causing the most serious health threat. (Vardoulakis et al., 2003). The 
53 thermal comfort of pedestrians is also related to the street canyon geometries

54 (Chatzidimitriou and Yannas, 2013; Syafii et al., 2017). The pedestrian wind environment

55 and thermal comfort could be improved by intentionally designing the street canyon (Du

56 et al., 2019). Understanding the airflow and pollutant dispersion within the urban street

57 canyon is important to the sustainability of the urban environment.

58 The wind flows in the street canyons are inherently complex and exhibit a wide range

59 of physical characteristics including large low-speed areas, strong pressure gradients,

60 unsteady flow regions, three-dimensional effects and wakes (Deck, 2005). These wind

61 flow mechanisms are strongly related to geometry configurations and incoming wind

62 directions. The most widely studied cases in the literature are those with wind

63 perpendicular to the street axis because they represent the worst situation for air pollutant

64 dispersion (Li et al., 2006). Under such wind direction, it is reasonable to assume that the

65 street is infinitely long. Then, the original complex 3-D problem could be simplified as a

66 2-D one.

67 There are two types of 2D cases in previous studies: pure (only 2 directions are

68 simulated) and quasi 2D (all three directions are simulated for a quasi-infinitely long

69 street canyon using lateral periodic boundary conditions). In the 2-D cases, the most

70 important geometrical feature of a street canyon is the aspect ratio, which is the height

$71(H)$ of the canyon being divided by the width $(W)$. Oke (1988) suggested that the flow

72 within 2-D street canyon could be described in terms of three regimes depending on the 
73 aspect ratio $(H / W)($ Oke, 1988). From a three-dimensional point of view, the length $(B)$,

74 which usually expresses the road distance between two major intersections of the canyon,

75 represents another important geometrical feature of the street canyon. The airflow in the

76 street ends is characterized by horizontal corner vortices. Soulhac et al., (2009) concluded

77 that the flow and dispersion at the street ends were dominated by a large vertical-axis

78 recirculating vortex, which has an important influence on exchanges between the streets

79 and overlying atmosphere. Carpentieri and Robins (2010) measured the mean and

80 turbulent tracer fluxes within several street intersections in a wind tunnel model of a real

81 urban area located in Central London. They found an increase in turbulent exchange at

82 roof level at the intersections (Carpentieri et al., 2012). Their later wind tunnel

83 measurements indicated that complex advective patterns appeared at intersections

84 composed of very simple and regular geometries (Carpentieri et al., 2018). Michioka et

85 al., (2014) conducted a series of large-eddy simulations of 3D street canyons with

86 multiple street lengths. Their simulations show that the mean concentration within the

87 canyon decreased with street length B due to stronger lateral dispersion. The DNS (direct

88 numerical simulation) study of Coceal et al. (2014) showed that the complicated flow

89 pattern had a significant influence on dispersion and mixing within the intersection. Based

90 on the wind tunnel measurements, Nosek et al., (2017) calculated the pollution flux

91 (turbulent and advective) at the lateral openings of three different 3D street canyons when

92 the wind was perpendicular and oblique to the along-canyon axis. Their results confirmed 
93 that the buildings' roof-height variability at the intersections plays an important role in

94 the dispersion of the traffic pollutants within 3D canyons.

95 Riain et al. (1998) summarized that the dispersion of gaseous pollutants in a street

96 canyon depended on the air exchange rate at the openings of street canyons, including the

97 roof of the street canyon and street ends. Vardoulakis et al. (2003) subdivided street

98 canyons into short $(B / H \approx 3)$, medium $(B / H \approx 5)$ and long canyons $(B / H \approx 7)$ based on the

99 street length. In relatively short canyons, corner vortices might be strong enough to inhibit

100 the formation of a stable vortex perpendicular to the street in the mid-section. With the

101 increase of street length, this ventilation effect will become less important (Theurer,

102 1999). Chan et al. (2001) found that the $B / H$ ratio can also affect the pollutant

103 concentration inside street canyons. Their later study found that the correlation between

104 pollutant concentration and $B / H$ is due to the vortices generated at the street ends (Chan

105 et al., 2003). Xue and Li (2017) simulated the pollutant dispersion within 3D street

106 canyons and found a maximum pollutant concentration at the symmetry plane and

107 minimum pollutant concentration at street ends. All these important features which are

108 evident in 3-D street canyons are normally neglected in the 2-D airflow and ventilation

109 simulations. In LES studies, although 3-D computation domain is widely used, the streets

110 are usually assumed as infinitely long by using periodic boundary condition at side

111 boundaries to reduce computational cost (Lateb et al., 2016). 
112 In the past two decades, there have been many modeling and experimental studies

113 focusing on 2-D canyon cases (Magnusson et al., 2014; Ngan and Lo, 2016; Marciotto

114 and Fisch, 2013; Koutsourakis et al., 2012). Previous studies show significant

115 differences in airflow and dispersion between 3-D and 2-D canyons (Nosek et al., 2017;

116 Xue and Li, 2017). However, it is still not clear when and how well the 2-D models could

117 represent the airflow and pollutant dispersion in the 3D scenarios. As many urban design

118 guidelines were based on previous studies with 2D model, it is necessary to find out the

119 differences between 3D and 2D simulations. Additionally, the 2D simulation can

120 extensively reduce the computational resource, especially at LES scenarios. In the near

121 future, the quasi-2D model is expected to be widely used in LES studies. The present

122 paper attempts to identify requirements that the ventilation at 3-D street canyon can be

123 represented by 2-D models. Specifically, the main research questions are:

124 - Can a 2-D model represent a real 3-D street canyon for street canyon ventilation

125 simulation?

126 Is there a minimum street length/height ratio that a 2-D model could represent a 3-D

127 street canyon?

128 These questions are explored by conducting a series of 3-D simulations with different

129 street lengths and comparing against a corresponding 2-D simulation. The ambient wind

130 is assumed perpendicular to the street direction at 3-D scenarios. Different indicators such

131 as $\mathrm{ACH}$, normalized concentration, retention time are used as metrics to evaluate the 
132 ventilation and air pollution dispersion performance. This paper is structured as follows.

133 The details of the model geometries and methodology are given in Section 2. In Section

1343 , the results are presented by looking at the flow and concentration fields along with

135 multiple ventilation indices. Conclusions are presented in Section 4.

136

\section{2. Methodology}

138 The airflow in the urban area is considered as isothermal and the buoyancy effect is

139 neglected. The time-averaged velocity and concentration fields are predicted using the

140 Reynolds-averaged Navier-Stokes equations (RANS). The open source CFD

141 (computational fluid dynamics) codes OpenFOAM v4.0 is used to solve governing

142 equations of fluid dynamics. The data from wind tunnel experiments carried out by

143 Tominaga and Stathopoulos (2011) is used to validate the computational model.

\section{2.1. Domain dimensions}

145 Figure 1 shows two types of street canyon model adopted here, including the isolated

146 street canyon (ISC) and the multiple street canyon (MSC). Perret et al (2017) evaluated

147 the large-scale unsteadiness of the shear layer separating from an upstream canyon edge

148 on the vertical mass-exchange of the street canyon by wind tunnel measurement. It is

149 suggested that the influence of the upstream buildings could not be simply ignored.

150 Therefore, for the MSC configuration, we consider four canyons upstream and three

151 canyons downstream of the target canyon. As the target canyon is far away from the flow

152 separation at the leading edge, the airflow pattern at downstream canyons keeps

153 unchanged (Mei et al., 2017). The width of the street canyons is fixed at $W=0.1 \mathrm{~m}$, while

154 the height of the buildings $H$ varies to form different aspect ratios $(H / W)$, i.e., $H / W=1.0$

155 and 2.0. All the cases considered fall into the skimming flow regime in the canyon (Oke,

156 1988). The building length $B$ varies from $4 W$ to $60 W$ and the ambient wind blows

157 perpendicular to the street canyon. The computational domain is selected based on the 
158 best practice guidelines for CFD simulation of urban aerodynamics (Franke, 2007;

159 Tominaga et al., 2008). The upstream distance and downstream distance are $5 H$ and 15

$160 H$ respectively. The domain height is $8 H$ and the side distances are $5 H$. A passive pollutant

161 is released at a line source at the centre of the street.

\section{2.2. Boundary conditions}

163 The inlet profiles are set based on the wind tunnel measurement of Tominaga and 164 Stathopoulos (2011). The vertical profile of mean velocity in the approaching flow

165 approximately obeys a power law with an exponent of 0.26 . The upwind mean velocity

$166 U_{\text {ref }}$ at building height $h(=W)$ is $3.8 \mathrm{~m} / \mathrm{s}$. A no-slip boundary condition is imposed at the 167 building surfaces and the bottom boundary of the domain. The ground and building 168 surface roughness are ignored in the simulation. The top and lateral boundaries of the 169 domain are set as free-slip. On the outflow boundary, a zero diffusive flux is imposed for

170 all flow variables in the direction normal to the outflow plane. This means that the 171 conditions of the outflow plane are extrapolated from within the domain. This assumption 172 is valid for fully developed flows.

\section{2.3. Computational meshes}

174 Unstructured hexahedral meshes are generated by snappyHexMesh (OpenCFD Ltd, 175 v4.0) using the cutCell assembly meshing function. The domain near the buildings and 176 ground contains the smallest grids, cubic cells with dimensions of $0.05 W \times 0.05 W \times$ $1770.05 \mathrm{~W}$. To reduce the computational load, sparser grids are used in the regions away from 178 the buildings and ground. The largest cubic cells are with dimensions of $0.2 W \times 0.2 W \times$ $1790.2 \mathrm{~W}$. The total number of grids ranges from 0.6 to 7.8 million, depending on buildings' $180 \quad$ length $B$ and canyon number.

181 The grid-independency test was conducted by comparing three types of mesh (coarse, 182 basic and refined mesh) for the single canyon case with $B / W=4$. The coarse and refined 183 meshes were built by reducing and increasing the mesh number between buildings by 1.5 184 times, respectively. The mean velocity and turbulent kinetic energy (TKE) at the middle 
185 line (along $y$-direction) at the roof of street canyon calculated between three meshes are

186 compared in Fig. 2. By further increasing the mesh number (from basic to refined mesh),

187 both velocity and turbulent kinetic energy (TKE) fields showed little changes, which

188 shows that the present grid is sufficiently dense for the present studies.

189

\section{2.4. Solution method}

191 The atmospheric air can then be assumed incompressible. In 2-D RANS modeling, the

192 flow properties are disintegrated into their mean and fluctuating components by Reynolds

193 decomposition and substituted in the Navier-Stokes equations, which could be written as:

$$
\frac{\partial \overline{u_{i}}}{\partial x_{i}}=0
$$

196

where $x_{i}$ are the Cartesian coordinates. The mean and fluctuating components of flow

197 properties are marked with overbar and apostrophe respectively. For example, $\overline{u_{i}}$

198 represents the components of the mean velocity. Here, $\bar{p}$ is the pressure, $\overline{u_{i}^{\prime} u_{j}^{\prime}}$ the

199 Reynolds stress tensor which remains after the hydrostatic pressure is removed. The

200 Reynolds stress tensor appearing in the mean momentum equation is modeled using the

201 Boussinesq's eddy viscosity model:

$$
-\overline{u_{i}^{\prime} u_{j}^{\prime}}=2 v_{t} \overline{S_{i j}}-\frac{2}{3} k \delta_{i j}
$$

203 where the strain rate tensor $\overline{S_{i j}}=\frac{1}{2}\left(\frac{\partial u_{i}}{\partial x_{j}}+\frac{\partial u_{j}}{\partial x_{i}}\right)-\frac{1}{3}\left(\frac{\partial u_{i}}{\partial x_{i}}\right) \delta_{i j}, k$ denotes the turbulent

204 kinetic energy and $v_{t}$ the turbulent viscosity. The RNG $k-\varepsilon$ model (Yakhot and Orszag, 
1986) is selected due to its generally good performance in predicting flow around

206 buildings (Tominaga and Stathopoulos, 2010). The steady transport equation for the time-

207 averaged pollutant concentration $\left(\bar{c}, \mathrm{~kg} / \mathrm{m}^{3}\right)$ is:

$$
\overline{u_{j}} \frac{\partial \bar{c}}{\partial x_{j}}=\frac{\partial}{\partial x_{j}}\left(K_{c} \frac{\partial \bar{c}}{\partial x_{j}}\right)+Q
$$

209 where $\overline{u_{j}}$ is the time-averaged velocity components, $Q$ is the pollutant emission rate,

$210 K_{\mathrm{c}}=v_{\mathrm{t}} / S_{\mathrm{ct}}$ is the turbulent eddy diffusivity of pollutants, $v_{\mathrm{t}}$ is the kinematic eddy viscosity,

$211 S_{\mathrm{ct}}=0.7$ is the turbulent Schmidt number (Di Sabatino et al., 2007).

212 All transport equations are discretized using a finite volume method. The hybrid second 213 order upwind/central differencing scheme is utilized to discretize the advection terms,

214 with an option of the second-order upwind scheme and the QUICK scheme (Patankar,

215 1980). The discretized differential equations are solved by the SIMPLE algorithm

216 (Patankar, 1980), which is solved by simpleFOAM solver in OpenFOAM .

217 Convergence is achieved when all scaled residuals are less than $10^{-5}$ and the average

218 flow speeds at several locations.

219

\subsection{Model validation}

Model validation is essential for CFD studies before further analysing. The accuracy of the current CFD model is demonstrated by comparing to the experimental database obtained from the wind tunnel at Niigata Institute of Technology (Tominaga and Stathopoulos, 2011). The three-dimensional canyon was characterized with $H / W=1.0$ and $H / B=0.5$. Ethylene $\left(\mathrm{C}_{2} \mathrm{H}_{4}\right)$ was used as a tracer gas and released at the centre of the street bottom with a concentration of $1000 \mathrm{ppm}$. The pollutant was released by a point source in their experiment. The atmospheric boundary flow profiles were produced by a combination of spires and surface roughness in their experiment. The velocity and turbulent profiles could be represented by $U(z)=U_{\text {ref }}(z / H)^{0.26} \cdot k(z)=(U(z) I(z))^{2}$, 
$230 \varepsilon=\sqrt{C_{\mu}} k(z) \frac{d U(z)}{d z}$, according to their measurement. The inlet profiles have been 231 compared to the measurement of Tominaga and Stathopolous (2011) in Fig. 3. Here, $232 U_{\text {ref }}=3.8 \mathrm{~m} / \mathrm{s} . C_{\mu}=0.0845$, is a constant in the RNG turbulent model, $I(z)$ is the turbulent 233 intensity.

234 The velocity vectors on the vertical and horizontal planes were compared with the wind 235 tunnel experiment in Figs. 4a and 4b. On the vertical section at the middle point, a single 236 recirculation flow was observed in the street canyons. On a horizontal section at $z / H=$ 237 0.1, two vortices appeared within the street canyons. The general patterns of the 238 recirculation flow in CFD were close to that in the experiment. Figure $4 d, 4 e$ and $4 f$ 239 compared the measured and calculated concentration $\bar{c}$ along the streamwise direction 240 (x). Overall, the CFD prediction of $\bar{c}$ is satisfactory. Despite overestimation is found at 241 the height of $z / H=0.1$, it is consistent with previous RANS simulations (Gromke et al., 242 2008; Tominaga and Stathopoulos, 2011). These differences were caused by 243 underestimated turbulence diffusions in lateral direction in RANS models.

244 In order to evaluate the predictions of a model with experimental observations, the 245 normalized mean square error (NMSE) recommended by Hanna et al. (1991) were used,

246 which represents the normalized discrepancy between the computed and experimental 247 values and is calculated as follows,

$$
N M S E=\frac{\sum_{i=1}^{n}\left(O_{i}-P_{i}\right)^{2}}{\sum_{i=1}^{n}\left(O_{i} P_{i}\right)}
$$

249 where $n$ represents the number of points, $O_{\mathrm{i}}$ represents the measurements at each point 250 and $\bar{O}$ is the measurement mean. $P_{\mathrm{i}}$ and $\bar{P}$ represent the computed values and the 251 corresponding mean at each point, respectively. A perfect model could have the 252 parametric values of $N M S E=0.0$. According to the recommended criteria by COST 
Action 732 (Efthimiou et al., 2011), 'state of the art' model performance has met the

254 following statistical metrics standard: NMSE $<1.5$. The calculated NMSE at the bottom

255 line, middle line and top line are $0.128,0.182$ and 0.412 , respectively. As the focus of the

256 present study is on evaluating the difference in pollutant dispersion between two-

257 dimensional and three-dimensional RNAS models, the numerical model used in this study

258 is considered reliable.

259

260 3. Results and discussion

\section{3.1. Three-dimensional street canyon airflow}

262 Dispersion within three-dimensional street canyon is heavily influenced by the flow

263 structure. Therefore, we begin by describing the basic flow pattern within a street canyon surrounded by urban buildings and subjected to perpendicular approaching wind, as shown in Fig. 5. Gromke and Ruck (2007) summarized that there are two distinguishable

266 flow characteristics, i.e., vertically rotating (recirculating with the along-canyon axis) canyon vortices and horizontally rotating (recirculating with the vertical axis) corner eddies. The canyon vortices are driven by shear forces of the skimming flow above the rooftop. Instead, the corner vortices are driven by the shear at street ends, which is induced by the channelling flow. The resulting flow in a 3-D street canyon could be more complex due to the interaction between the corner vortices and canyon vortices. Becker et al. (2002) and Kim and Baik (2004) found a portal vortex behind the upwind building, which extends toward the lower edges of the downwind building.

274 The flow structure is depicted by tracing a set of streamlines originated from multiple

275 seed locations on a straight line above the line source $(z / H=0.1)$, shown in Fig. 6 . The 276 streamlines are coloured by mean velocity. Here, cases with $B / W=4$ are selected for

277 illustration. The basic characteristics described by Gromke and Ruck (2007) are also 
278 found in streamlines. However, for the ISC configuration, the corner vortices extend 279 beyond the street ends toward the upwind corner. This is because of the reverse flow near 280 the side walls induced by the flow separation (Murakami and Mochida, 1989). In contrast, 281 the corner vortices are well confined within the canyon volume in the MSC configuration. 282 This is because the target canyon is far away from the leading building and not influenced 283 by the flow separation. The $y / B=0$ planes represent the symmetrical planes and $y / B=$ $284 \pm 0.5$ represent the street ends.

285 The $x$-velocity was filtered as zero to transfer the 3D streamlines to 2D streamlines. 286 The 2D streamlines in the ISC case $(B / W=4)$ were plotted at planes parallel to the street 287 direction to show the flow structure along the street direction. The planes were located at 288 the centrelines of the streets, shown as Fig. 7. A counter-rotating flow structure was 289 observed at the $y-z$ plane. This flow structure induced ambient air from the street ends 290 into the street canyon volume. The inlet flows at two street ends were of opposite 291 directions and collided at the symmetry plane, resulting with an upward flow.

292 It is interesting to note that mean streamlines escapes from the canyon roof at the 293 symmetrical planes, instead of recirculating below roof level. When the streamlines 294 recirculate below the roof level, the pollutant is transported mainly due to turbulence 295 (Buccolieri et al., 2009). However, the mean upward flow extended beyond the roof level 296 could extensively raise the mass transfer rate. Fig. 8 shows contours plots of the 297 normalized vertical velocity $w^{*}\left(=w / U_{\text {ref, }}\right.$ where $w$ is the mean vertical velocity $)$ at two 298 different height $z=0.1 \mathrm{H}$ and $z=1.0 \mathrm{H}$. Strong upward flow is observed at both heights.

299 The upward flow is confined within a narrow area adjacent to the upwind buildings except 300 at the symmetrical planes, where the upward flow extends across the whole street canyon 301 width. This indicates that pollutants may be transferred directly from ground level to roof 302 level at symmetrical planes (refers to the $x-z$ plane at $y=0$ ). This statement could be 303 supported by abnormal pollutant concentration decay at that position, which is also 304 observed in previous wind tunnel experiment (Gromke, 2011; Gromke and Ruck, 2012) 
and CFD simulations (Jeanjean et al., 2015). In fact, the concentration drop in the

306 symmetry plane is not common in previous studies. There are several reasons: 1) the point

307 sources instead of line sources were used in previous 3D street canyon studies; 2) the

308 concentration drops were only observed at specific street length range; when street is long

309 enough, the concentration drop is no longer obvious, as shown as Fig. 15. 3) the

310 surrounding buildings (with intersections) are ignored in the present studies, which could

311 potentially suppress the horizontal convergence flow, as shown in Fig. 7

\section{3.2. Pollutant dispersion at the three-dimensional street canyon}

313 To facilitate the comparison among the 2-D and 3-D simulations, dimensionless 314 concentration $C$ is introduced as a function of the simulated pollutant concentration $\bar{C}$

$315\left(\mathrm{~kg} / \mathrm{m}^{3}\right)$, reference wind speed $U_{\text {ref }}(\mathrm{m} / \mathrm{s})$, height of the building $H(\mathrm{~m})$, length of the line 316 source $B(\mathrm{~m})$, and ethane flow rate $Q(\mathrm{~kg} / \mathrm{s})$ (Meroney et al., 1996),

$$
C=\frac{\bar{c} U_{r e f} H B}{Q}
$$

The dimensionless concentration fields at three $x-z$ planes of 3-D street canyons along with the corresponding 2-D cases are shown in Fig. 9 and Fig. 10. Generally, the concentration distributions in these planes of 3-D simulation are different than those in

322 the case of the $2 \mathrm{D}$ canyon. The concentration levels are appreciably lower at $y / B=0$

323 planes, which is due to strong upward flow as described in the former section. The pollutant concentration are even lower at the $y / B=0.45$ planes, where are close to the street ends. The corner vortices at street ends could significantly enhance the local dilution rate (Buccolieri et al., 2009). An appreciably higher concentration is observed at

327 the street level at $y / B=0.25$ planes, which is quite different from 2-D canyon. This indicates the convergence flow along the street direction has non-negligible influence on the pollutant dispersion. These differences remain at the very long street $(B / W=60)$. It 
330 should be cautious when applying 2-D model to predict the pollutant distribution in street

331 canyon

332

333

\subsection{Ventilation in the street canyon}

334 The pollutant dilution at the 2-D street canyon is governed by the air exchange at roof 335 level, while for the 3-D street canyon, ventilation both at the roof level and street ends will play its role. The averaged $A C H_{\text {roof }}$ (Hang and $\mathrm{Li}, 2010$ ) is used to evaluate the air exchange at the street canyon roof, which is divided into the mean component:

$$
\overline{\mathrm{ACH}}_{\text {roof }}=\frac{1}{H B W} \int_{\Gamma_{\text {roof }}} \overline{\mathrm{w}}_{+} d x d y
$$

and the turbulent component:

$$
A C H^{\prime}{ }_{\text {roof }}=\frac{1}{H B W} \int_{\Gamma_{\text {roof }}} \frac{1}{2} \sqrt{\overline{w^{\prime} w^{\prime}}} d x=\frac{1}{H B W} \int_{\Gamma_{\text {roof }}} \sqrt{\left[\frac{k}{6}-\frac{1}{2} v_{t}\left(\frac{\partial \bar{w}}{\partial z}\right)\right]} d x d y,
$$

where $w$ is the vertical velocity component, $v_{\mathrm{t}}$ the turbulent viscosity and $\Gamma_{\text {roof }}$ the roof area of the street canyon. The subscript + signifies that only the upward velocity $w>0$ (i.e., air removal) is considered.

344 Similarly, the $A C H_{\text {side }}$ at street ends is calculated as:

$$
\overline{\mathrm{ACH}}_{\text {side }}=\frac{1}{H B W} \int_{\Gamma_{\text {side }}}{\overline{\mathrm{v}_{+}}}_{d x} d z
$$

where $v$ is the velocity ay $y$-direction component and $\Gamma_{\text {side }}$ the street ends area of the street canyon. The subscript + signifies that only the outward velocity $v>0$ (i.e., air removal) is considered. It should be noted that the $v_{+}$for one street end and $v_{\text {- }}$ for the opposite street end. The total ventilation for street canyon $A C H_{c}$ will be the sum of $A C H_{\text {roof }}$ and $A C H_{\text {side }}$

$$
A C H_{c}=A C H_{\text {roof }}+\mathrm{ACH}_{\text {side }}
$$


The air exchange rate and its mean and turbulent components at canopy roof as a

353 function of the street length are presented at Fig. 11. The $A C H$ at 2-D simulations is 354 plotted as blue lines. It is found that the $\mathrm{ACH}_{\text {roof }}$ contributed by mean flow is smaller than 355 turbulent fluctuation for all cases. In the MSC configuration, the mean flows in that 356 configuration are parallel to the roof surfaces, resulting with weak mean vertical flow.

357 Therefore, the turbulent fluctuation $\left(A C H_{\text {roof }}^{\prime}\right)$ dominants the air exchange at roof level.

358 Compared to the MSC configuration, the mean flow in the ISC configuration plays a more significant role in the air exchange due to flow separation. It was found that $A C H_{\text {roof }}$ were

360 almost unchanged with the increase of street length when streets were long enough.

361 However, the variation trend varies from case to case. For isolated canyon with $H / W=$ 3621.0 , the $A C H_{\text {roof }}$ increases significantly with the street length. When we increase the $H / W$ 363 to 2.0 at isolated canyon cases, the $A C H_{\text {roof }}$ decreases firstly before increases 364 monotonically. This could be due to the flow separation at street ends, which may 365 decrease the shear at roof level.

366 The air exchange rate and its mean and turbulent components at street ends as a function 367 of the street length are presented at Fig. 12. In contrast to street canyon roof, the $A C H_{\text {side }}$ 368 has a negative relation with the street length. This explained why there is a peak value for the $A C H_{c}$. The functions between the $A C H_{c}$ and street length are plotted in Fig. 13. When

370 initially increasing the street length, the decrease of $A C H$ at street ends plays a dominant 371 role. As a result, the total $A C H$ increases with the street length. When further increasing 372 the street length, the increase of the $A C H$ at street roof plays a dominant role. Therefore, 373 the total $A C H$ decreases with the street length when $B / W$ is longer than 30 .

374 As shown in the flow field at Fig. 6 and Fig. 7, the street length has two opposite effects 375 on the pollutant dispersion. Firstly, with the increase of the street length, the corner vortices have less impact on the pollutant dilution of the whole canyon volume. As a

377 result, the pollutant concentration increased with street length. Secondly, the interaction

378 between the corner vortices and canyon vortices would also be weakened when increasing 
379 the street length. As a result, the pollutant concentration would decrease with street

380 length. With continue increasing the street length, the first effect dominants the pollutant

381 dilution and the second one gradually disappears.

382

\subsection{Retention time at street canyon}

384 The ventilation performance of the whole canyon will be evaluated by the canyon retention time $\tau_{\mathrm{c}}$ (Cheng et al., 2008), calculated as:

$$
\begin{gathered}
\Theta=\frac{1}{V} \iiint c d x d y d z \\
\tau_{c}=\frac{\Theta \times V}{Q}
\end{gathered}
$$

where $c$ is the local concentration of a passive tracer gas $\left(\mathrm{kg} / \mathrm{m}^{3}\right)$, and $Q$ is the pollutant emission rate $(\mathrm{kg} / \mathrm{s})), V$ the volume of the street canyon. The average pollutant concentration $\Theta$ signifies the overall air quality of the street canyon while $\tau_{\mathrm{c}}$ represents the time scale for a parcel of pollutant being removed from the street canyon.

Figure 14 shows the canyon retention time as a function of the street length. The canyon retention time of 2-D simulation is plotted as blue dash lines. The most important goal for the present study is to find the minimum street length that 2-D simulation can represent the ventilation of 3-D street canyon. In ISC configuration, the minimum street lengths are $20 \mathrm{~W}$ and $70 \mathrm{~W}$ for $H / W=1.0$ and 2.0 respectively. In MSC configuration, the minimum street lengths are $20 \mathrm{~W}$ and $50 \mathrm{~W}$ for $H / W=1.0$ and 2.0 respectively.

The canyon retention time increases firstly and then decreases to a constant value with the increasing street length. Additionally, the peak value increases with the aspect ratio

$400(H / W)$. In the ISC configuration, the canyon retention time reaches its maximum value at $B / W=6$ for $H / W=1.0$ and at $B / W=20$ for $H / W=1.0$. In the MSC configuration, the maximum value of retention time corresponds to $B / W=8$ and 20 for $H / W=1.0$ and 2.0, respectively. This is just opposite to variation of the total $A C H$, which indicates that the

404 air exchange at street openings dominates the pollutant dilution at these cases. 

quantities inside the street canyon, i.e.

$$
\begin{gathered}
\Omega_{\text {canyon }}=\{(x, z):-0.5 W \leq x \leq 0.5 W,-0.5 B \leq y \leq 0.5 B, 0 \leq z \leq H\}: \\
\bar{\varphi}=\frac{B}{Q W H} \int_{-0.5 W}^{0.5 W} \int_{0}^{H} c(x, z) d x d z
\end{gathered}
$$

In other words, $\bar{\varphi}$ denotes an average retention time along the $y$-direction.

410 Figure 15 shows the distribution of retention time along the street direction ( $y$ 411 direction). For the ISC configuration with $H / W=1.0$, the retention time decreases 412 significantly at the street end, indicating the corner vortices enhanced local dilution rate.

413 Toward the symmetrical planes, the retention time rises rapidly before significant 414 declining in a narrow zone at the symmetrical planes. As explained before, pollutants 415 could be transferred directly from ground level to roof level at symmetrical planes. With 416 the increase of street length, the rise of retention time disappears at symmetrical planes.

417 This indicates that the increase in retention time is caused by interaction between canyon 418 vortex and corner vortices.

419 For the ISC configuration with $H / W=2.0$, a significant increase of local retention time 420 is found at the street ends. It could be caused by the of corner vortices, which can become more strength at the deep street canyon. However, the increase of retention time at street ends is not found in multiple canyon cases. This suggests that the corner vortices are not driven by shear force at street ends as suggested by Gromke and Ruck (2007). Instead, they are resulted from flow separation at side walls. Such difference could be due to the fact that the skimming flow regime is chosen in the present study.

\subsection{Limitations}

Although the present RANS model provides satisfactory accuracy, the unsteadiness of the turbulence could not be reproduced. Studies with LES or DNS model are still expected, which could provide more information about the turbulent fluctuation.

430 Moreover, in some previous studies (e.g., Soulhac et al. (2009), Michioka et al. (2014)), 
431 that the spatially averaged concentration is the highest at this central plane. In other

432 studies, abnormal concentration decay was found at the central plane (Gromke, 2011;

433 Gromke, and Ruck, 2012). Although we have made some new insight on this issue, there

434 is also a clear need for a set of wind tunnel experimental studies in the future to support

435 our observations. It should also be noted that isolated street canyons instead of street

436 canyons embodied in an urban street network were analysed here. The local flow

437 characteristics could also be affected by surrounding buildings especially intersections.

438

439 4. Conclusions

440 In this study, the differences between 2-D and 3-D RANS simulations on resolving the 441 ventilation at street canyon are investigated. The focus is on identifying the threshold 442 value of street length $(B)$ that 2-D results can well represent real 3-D street canyon. Here 443 the skimming flow regime is considered with two aspect ratios $(H / W=1.0$ and 2.0$)$ for 444 their wide adoption in previous studies. Both isolated street canyon (ISC) and multiple 445 street canyon (MSC) configurations are considered. The air exchange rate and pollutant 446 retention time are used to evaluate the ventilation and pollution dispersion inside the street 447 canyon.

448 With the increase of street length, the differences in ventilation between 3-D and 2-D 449 simulation become insignificant, although there still exists a minor difference between 450 them. A narrow zone with strong upward flow is found at the symmetrical planes at the 451 leeward wall of the street canyon, where an enhanced ventilation is observed. The 452 interaction between this upward flow and vertically rotating vortices at street ends leads 453 to the distinctions between the 3-D and 2-D simulations.

454 With the increase of street length, the averaged retention time of 3-D simulation 455 approaches 2-D simulation. The differences in retention time between 2-D and 3-D 456 simulations disappear when $B / W$ is larger than 20 for $H / W=1.0$ and 70 for $H / W=2.0$. In 
the MSC configuration, the differences disappear when $B / W$ is larger than 20 for $H / W=$ 1.0 and 50 for $H / W=2.0$.

459 The correlation between the street length and ventilation capacity could be used in 460 optimizing the urban street design to achieve better air quality. For example, the street 461 length with maximum pollutant accumulation should be avoided in urban design. Additionally, this study could be used in locating the monitoring point for air quality measurement in the street canyons. Monitoring facilities installed in street ends will underestimate the air pollution and overestimate the air pollution at central points.

\section{Acknowledgments}

467 The first author wishes to acknowledge the financial support from Wuhan University. 468 Prof. Fu-Yun Zhao would also like to acknowledge the financial support from the Natural 469 Science Foundation of China (NSFC Grant No. 51778504), Fundamental Research 470 Projects from Shenzhen Government (Grant No. JCYJ20160523160857948), and 471 National Key Research and Development Program of the Ministry of Science and 472 Technology of China (Grant No. 2018YFC0705201, Grant No. 2018YFB0904200).

\section{$474 \quad$ References}

475 Becker, S., Lienhart, H., Durst, F., 2002. Flow around three-dimensional obstacles in 476 boundary layers. Journal of Wind Engineering and Industrial Aerodynamics 90, 265$477 \quad 279$.

478 Buccolieri, R., Gromke, C., Di Sabatino, S., Ruck, B., 2009. Aerodynamic effects of trees 479 on pollutant concentration in street canyons. Science of The Total Environment 407, $480 \quad 5247-5256$.

481 Carpentieri, M., Robins, AG., 2010. Tracer flux balance at an urban canyon intersection. $482 \quad$ Boundary-layer meteorology 135(2), 229-242. 
Carpentieri, M., Hayden, P., Robins, AG., 2012. Wind tunnel measurements of pollutant turbulent fluxes in urban intersections. Atmospheric Environment 46, 669-674.

Carpentieri, M., Robins, AG., Hayden, P., Santi, E., 2018. Mean and turbulent mass flux measurements in an idealised street network. Environmental pollution 234, 356-367.

Chan, A.T., Au, W.T.W., So, E.S.P., 2003. Strategic guidelines for street canyon 488 geometry to achieve sustainable street air quality_part II: multiple canopies and canyons. Atmospheric Environment 37, 2761-2772.

Chan, A.T., So, E.S., Samad, S.C., 2001. Strategic guidelines for street canyon geometry to achieve sustainable street air quality. Atmospheric Environment 35, 4089-4098.

Chatzidimitriou, A., Yannas, S., 2017. Street canyon design and improvement potential for urban open spaces; the influence of canyon aspect ratio and orientation on microclimate and outdoor comfort. Sustainable cities and society 33, 85-101.

Cheng, W.C., Liu, C.H., Leung, D.Y.C., 2008. Computational formulation for the evaluation of street canyon ventilation and pollutant removal performance. Atmospheric Environment 42, 9041-9051.

Coceal, O., Goulart, E.V., Branford, S., Glyn Thomas, T., Belcher, S.E., 2014. Flow structure and near-field dispersion in arrays of building-like obstacles. Journal of Wind Engineering and Industrial Aerodynamics 125, 52-68.

Deck, S., 2005. Zonal-Detached-Eddy Simulation of the Flow Around a High-Lift Configuration. AIAA Journal 43, 2372-2384.

Di Sabatino, S., Buccolieri, R., Pulvirenti, B., Britter, R., 2007. Simulations of pollutant dispersion within idealised urban-type geometries with CFD and integral models. Atmospheric Environment 41(37), 8316-8329.

Du, Y., Mak, CM., Li, Y., 2019. A multi-stage optimization of pedestrian level wind environment and thermal comfort with lift-up design in ideal urban canyons. Sustainable Cities and Society 101424. 
509 Efthimiou, G., Santiago, J., Martilli, A., 2011. COST 732 in Practice: the MUST $510 \quad$ ModelEvaluation Exercise.

511 Franke, J., et al., 2007. The COST 732 Best Practice Guideline for CFD simulation of 512 flows in the urban environment: a summary. International Journal of Environment $513 \quad$ and Pollution 44.1.

514 Gromke, C., Buccolieri, R., Di Sabatino, S., Ruck, B., 2008. Dispersion study in a street 515 canyon with tree planting by means of wind tunnel and numerical investigations 516 Evaluation of CFD data with experimental data. Atmospheric Environment 42, $517 \quad 8640-8650$.

518 Gromke, C., Ruck, B., 2007. Influence of trees on the dispersion of pollutants in an urban 519 street canyon-Experimental investigation of the flow and concentration field. $520 \quad$ Atmospheric Environment 41, 3287-3302.

521 Gromke, C., 2011. A vegetation modeling concept for building and environmental 522 aerodynamics wind tunnel tests and its application in pollutant dispersion studies.

524 Gromke, C., Ruck, B., 2012. Pollutant concentrations in street canyons of different aspect 525 ratio with avenues of trees for various wind directions. Boundary-Layer Meteorology, 144(1), 41-64.

Hanna, S.R., Strimaitis, D.G., Chang, J.C., 1991. Hazard Response Modelling Uncertainty (A Quantitative Method) Volume II. Evaluation of Commonly-used Hazardous Gas Dispersion Model, Report F08635-89-C-0136, Sigma Research Corporation, Air Force Engineering andService Center, Tyndal Air Force Base

532 Hang, J., Li, Y., 2010. Wind conditions in idealized building clusters: macroscopic 533 simulations using a porous turbulence model. Boundary-layer meteorology 136, 129-159. 
Jeanjean, A. P., Hinchliffe, G., McMullan, W. A., Monks, P. S., Leigh, R.J., 2015. A CFD study on the effectiveness of trees to disperse road traffic emissions at a city scale. Atmospheric Environment 120, 1-14.

Kim, J.-J., Baik, J.-J., 2004. A numerical study of the effects of ambient wind direction on flow and dispersion in urban street canyons using the RNG $k-\varepsilon$ turbulence model. Atmospheric Environment 38, 3039-3048.

Koutsourakis, N., Bartzis, J.G., Markatos, N.C., 2012. Evaluation of Reynolds stress, kepsilon and RNG k-epsilon turbulence models in street canyon flows using various experimental datasets. Environmental Fluid Mechanics 12, 379-403.

Lateb, M., Meroney, R.N., Yataghene, M., Fellouah, H., Saleh, F., Boufadel, M.C., 2016. On the use of numerical modelling for near-field pollutant dispersion in urban environments - A review. Environmental Pollution 208, 271-283.

Li, X.-X., Liu, C.-H., Leung, D.Y., Lam, K., 2006. Recent progress in CFD modelling of wind field and pollutant transport in street canyons. Atmospheric Environment 40, $5640-5658$.

Magnusson, S., Dallman, A., Entekhabi, D., Britter, R., Fernando, H.J.S., Norford, L., 2014. On thermally forced flows in urban street canyons. Environmental Fluid

Marciotto, E.R., Fisch, G., 2013. Wind tunnel study of turbulent flow past an urban canyon model. Environmental Fluid Mechanics 13, 403-416.

Mei, S.-J., Hu, J.-T., Liu, D., Zhao, F.-Y., Li, Y., Wang, Y., Wang, H.-Q., 2017. Wind driven natural ventilation in the idealized building block arrays with multiple urban

Meroney, R.N., Pavageau, M., Rafailidis, S., Schatzmann, M., 1996. Study of line source morphologies and unique package building density. Energy and Buildings 155, 324characteristics for 2-D physical modelling of pollutant dispersion in street canyons. Journal of Wind Engineering and Industrial Aerodynamics 62, 37-56. 
562 Michioka, T., Takimoto, H., Sato, A., 2014. Large-eddy simulation of pollutant removal 563 from a three-dimensional street canyon. Boundary-layer meteorology 150(2), 259564275.

565 Murakami, S., Mochida, A., 1989. Three-dimensional numerical simulation of turbulent 566 flow around buildings using the $k-\varepsilon$ turbulence model. Building and Environment 24, 51-64.

Ngan, K., Lo, K.W., 2016. Revisiting the flow regimes for urban street canyons using the numerical Green's function. Environmental Fluid Mechanics 16, 313-334.

570 Nosek, Š., Kukačka, L., Jurčáková, K., Kellnerová, R., Jaňour, Z., 2017. Impact of roof 571 height non-uniformity on pollutant transport between a street canyon and intersections. Environmental Pollution 227, 125-138.

574

Oke, T.R., 1988. Street design and urban canopy layer climate. Energy and buildings 11, 103-113.

Patankar, S., 1980. Numerical heat transfer and fluid flow. CRC Press.

576 Perret, L., Blackman, K., Fernandes, R., Savory, E., 2017. Relating street canyon vertical mass-exchange to upstream flow regime and canyon geometry. Sustainable cities and society $30,49-57$.

Riain, C.M., Fisher, B., Martin, C.J., Littler, J., 1998. Flow Field and Pollution Dispersion in a Central London Street. Environmental Monitoring and Assessment 52, 299-314.

Soulhac L, Garbero V, Salizzoni P, et al. Flow and dispersion in street intersections [J]. Atmospheric Environment, 2009, 43(18): 2981-2996.

584 Syafii, NI., Ichinose, M., Kumakura, E., Jusuf, SK., Chigusaa, K., Wong, NH., 2017. Thermal environment assessment around bodies of water in urban canyons: A scale model study. Sustainable cities and society $34,79-89$.

587 Theurer, W., 1999. Typical building arrangements for urban air pollution modelling. Atmospheric Environment 33, 4057-4066. 
589 Tominaga, Y., Mochida, A., Yoshie, R., Kataoka, H., Nozu, T., Yoshikawa, M.,

590 Shirasawa, T., 2008. AIJ guidelines for practical applications of CFD to pedestrian

591 wind environment around buildings. Journal of Wind Engineering and Industrial

$592 \quad$ Aerodynamics 96, 1749-1761.

593 Tominaga, Y., Stathopoulos, T., 2010. Numerical simulation of dispersion around an 594 isolated cubic building: Model evaluation of RANS and LES. Building and $595 \quad$ Environment 45, 2231-2239.

596 Tominaga, Y., Stathopoulos, T., 2011. CFD modeling of pollution dispersion in a street 597 canyon: Comparison between LES and RANS. Journal of Wind Engineering and $598 \quad$ Industrial Aerodynamics 99, 340-348.

599 Vardoulakis, S., Fisher, B.E., Pericleous, K., Gonzalez-Flesca, N., 2003. Modelling air 600 quality in street canyons: a review. Atmospheric environment 37, 155-182.

601 Xue, F., Li, X., 2017. The impact of roadside trees on traffic released PM10 in urban 602 street canyon: Aerodynamic and deposition effects. Sustainable cities and society $603 \quad 30,195-204$.

604 Yakhot, V., Orszag, S.A., 1986. Renormalization-group analysis of turbulence. Physical 605 review letters 57, 1722.

606 
607 Figures and tables

608 Figure 1

609

610

611

612

613

614

615

616

617

618

619

620

621
Side houndarv

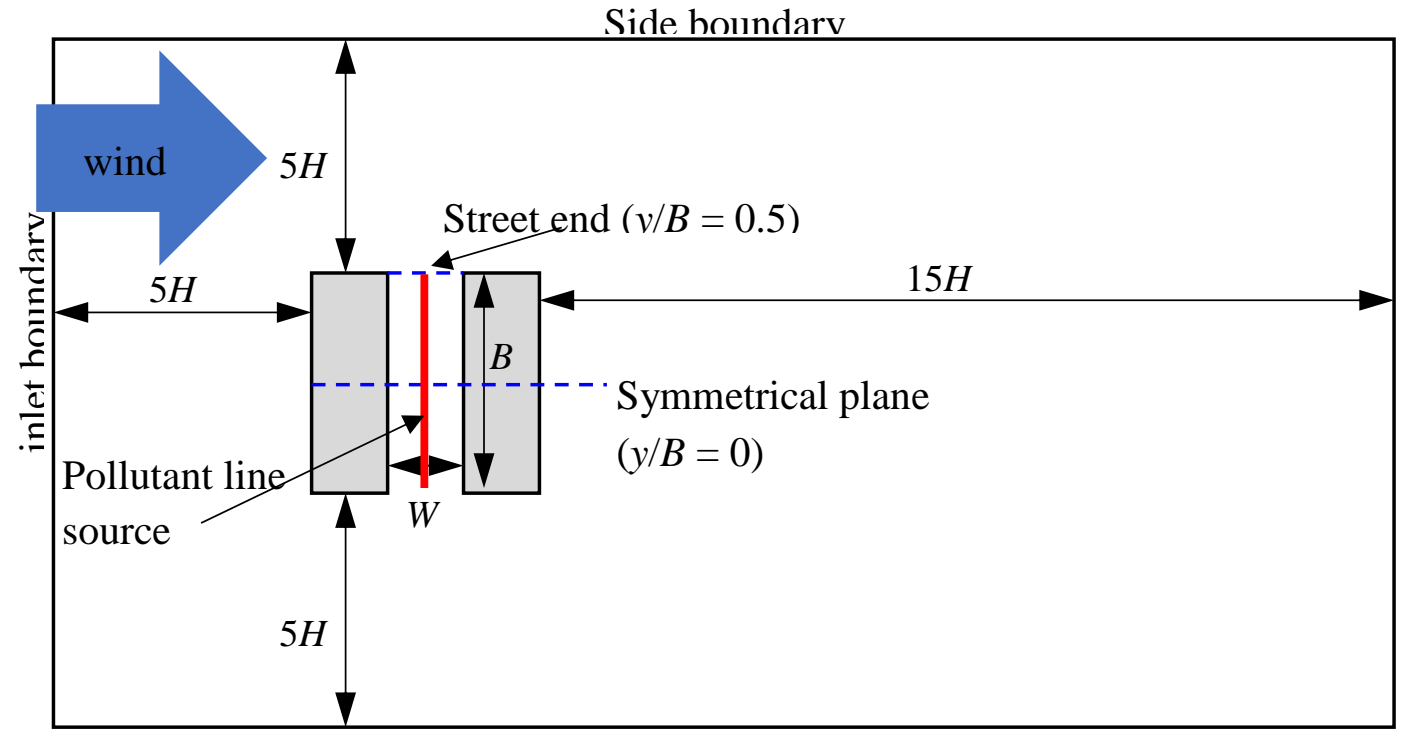

Side houndarv

(a)

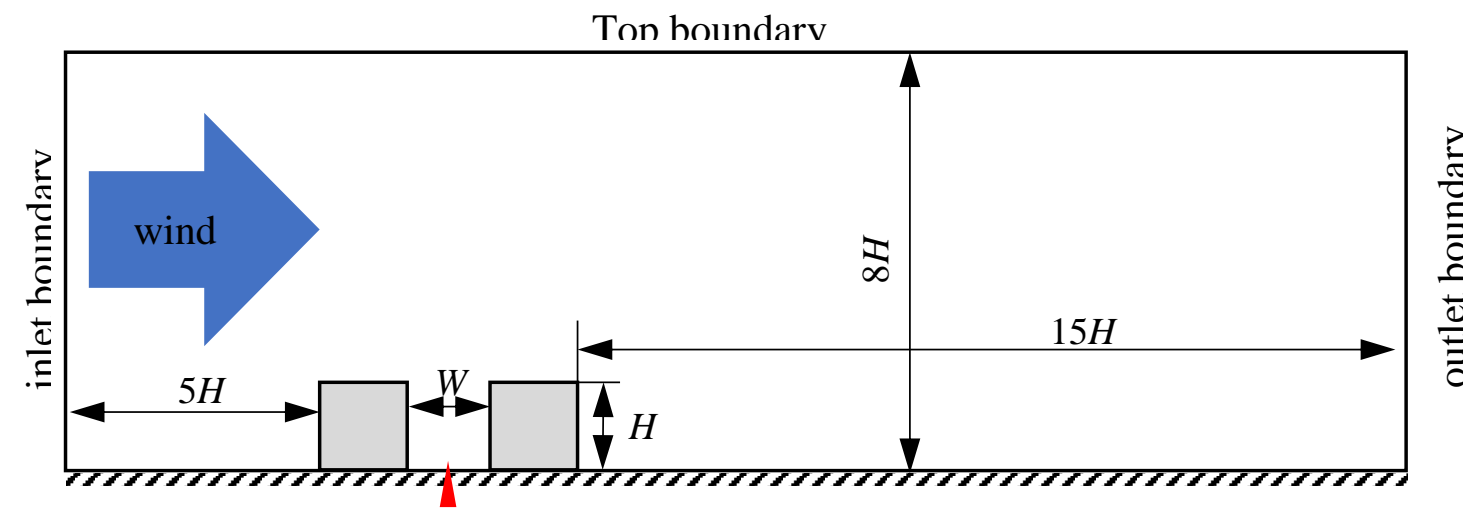

Pollutant line source

(b) 


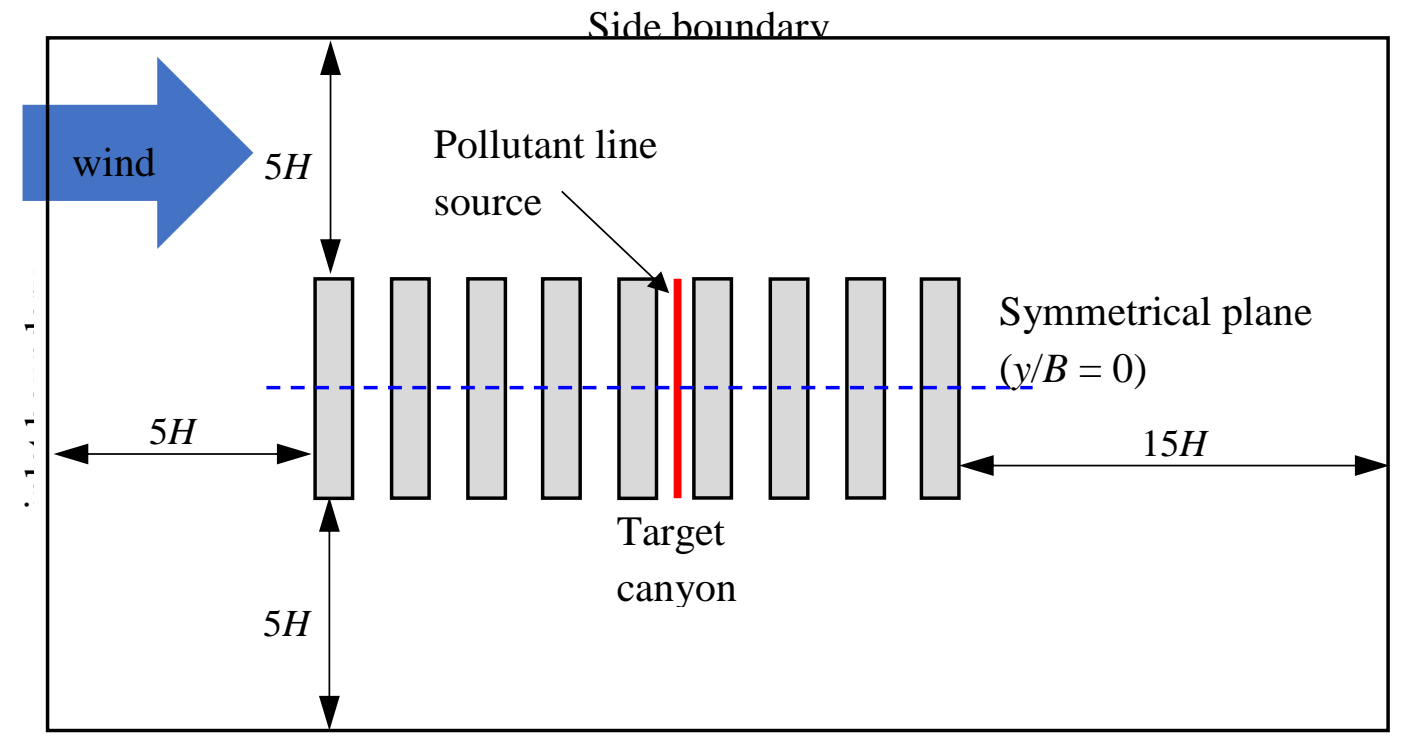

Side houndarv

(c)

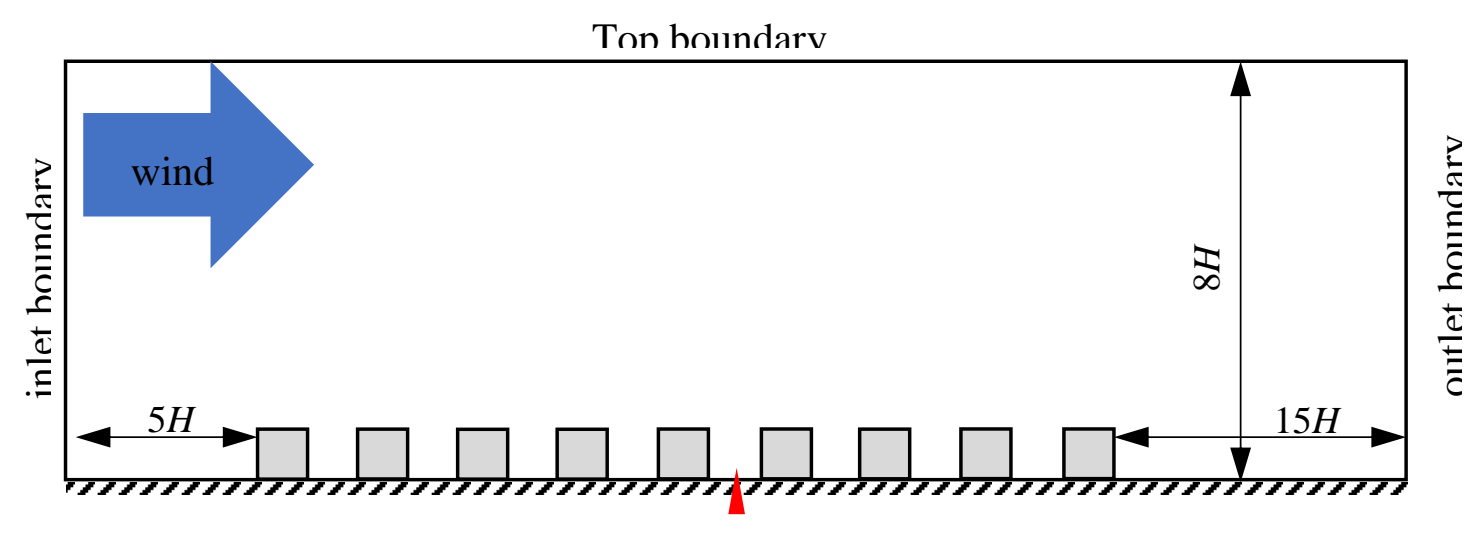

Pollutant line source

(d)

Fig. 1. Schematic view of computational domains used in CFD studies: (a) top view for isolated canyon and (b) side view for isolated canyon configuration, (c) top view for multiple canyons and (d) side view for multiple canyons configuration.

633

634

635

636

637 
639

640

641

642

643

644

645

646

647

648

649
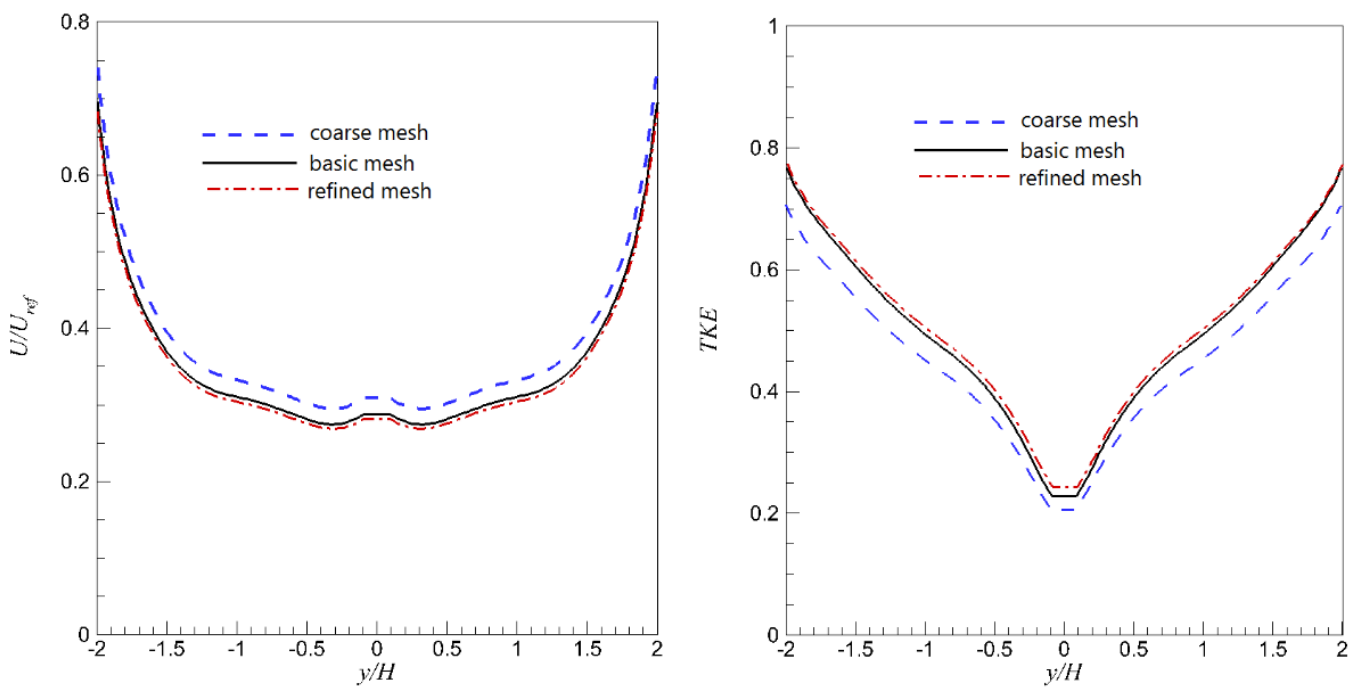

650

651 Fig. 3. Comparison of mean velocity (a) and turbulent kinetic energy (TKE) (b) at middle 652 line (along $y$-direction) at the roof of single canyon case with $B / W=4$.

653 
655

656

657

658

659

660

661

662

663

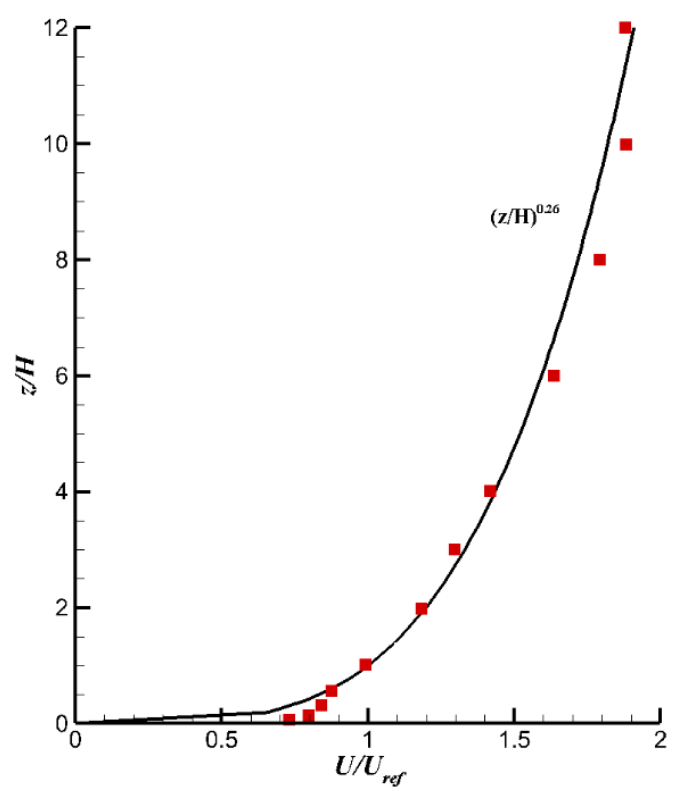

(a)

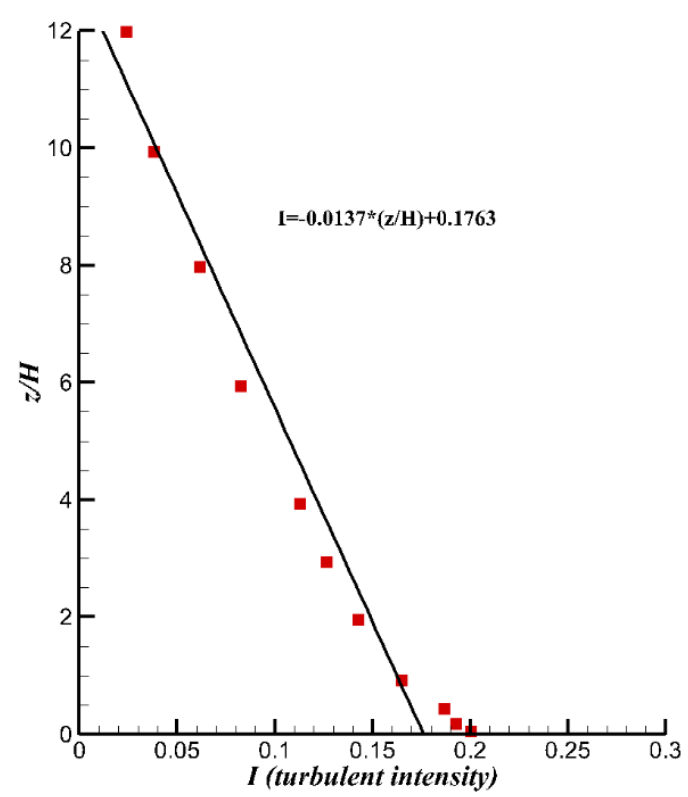

(b)

664 Fig. 3. Comparisons of CFD inlet velocity (a) and turbulent intensity (b) profiles with 665 measurements from Tominaga and Stathopolous (2011). 


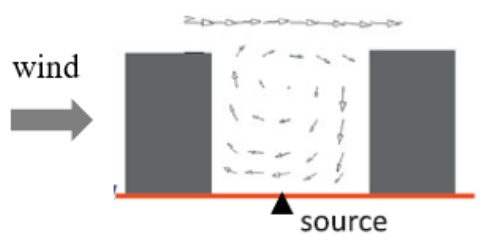

EXP Tominaga et al., (2011)

(a)

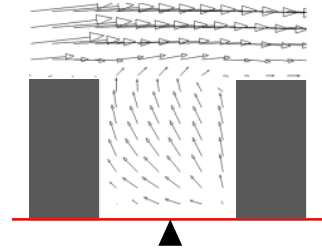

Present study

672

673

674

675

676

677

678
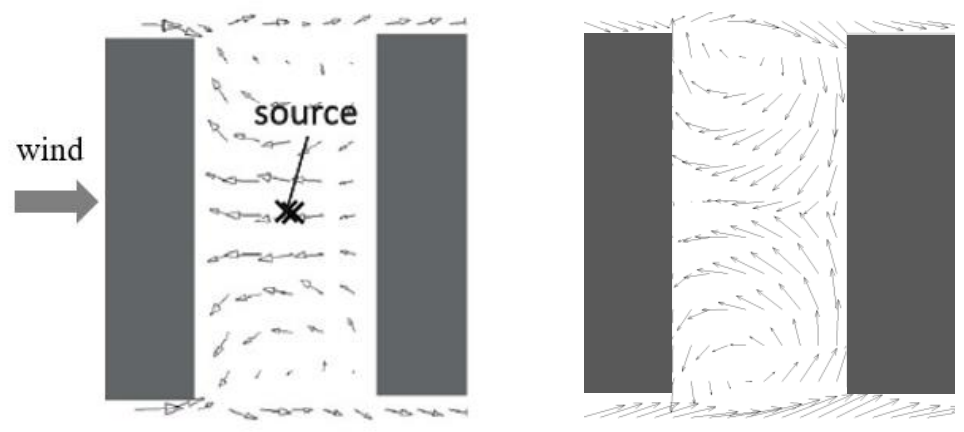

EXP Tominaga et al., (2011)

Present study

(b)

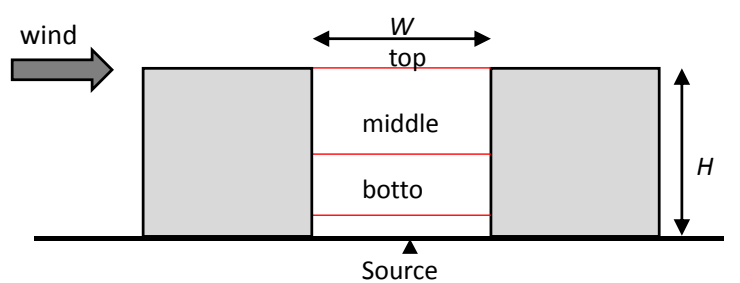

(c)

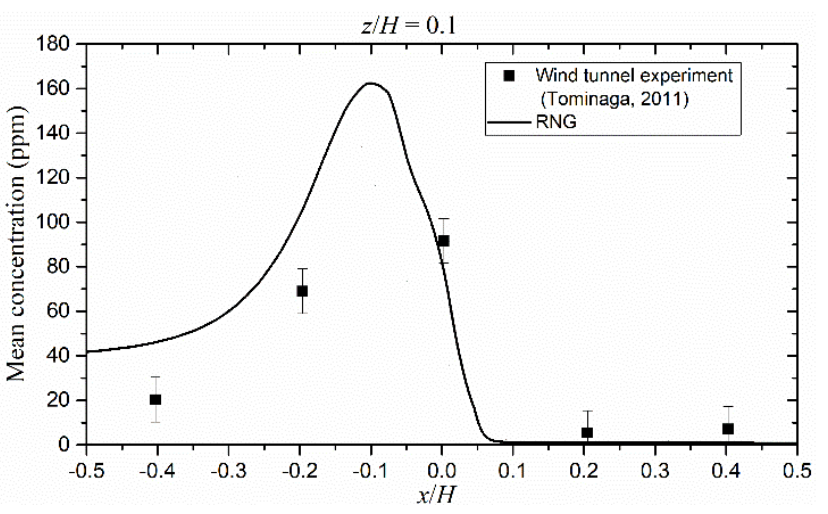

(d) Bottom line $(z / H=0.1)$ 
681

682

683

684

685

686 Fig. 4. Comparation of time-averaged concentration $c$ inside a street canyon at three 687 different heights of the symmetrical plane between the present RNG $k-\varepsilon$ simulation and 688 previous wind tunnel experiment.

(e) Middle line $(z / H=0.5)$

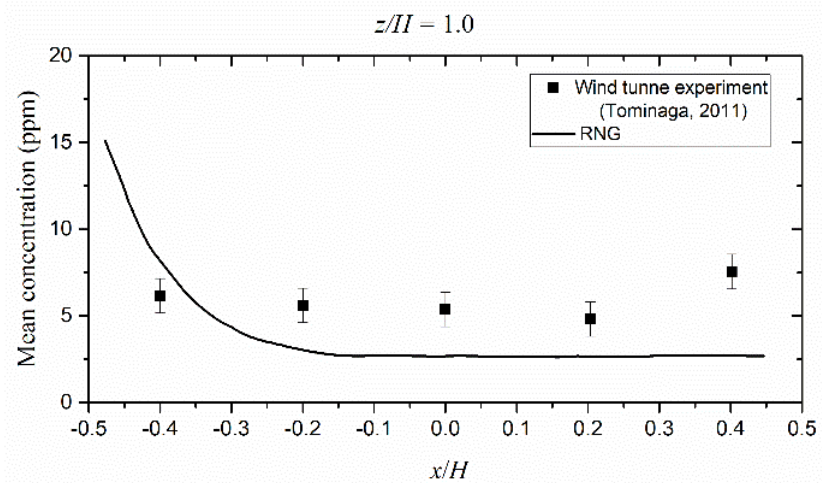

(f) top line $(z / H=1.0)$

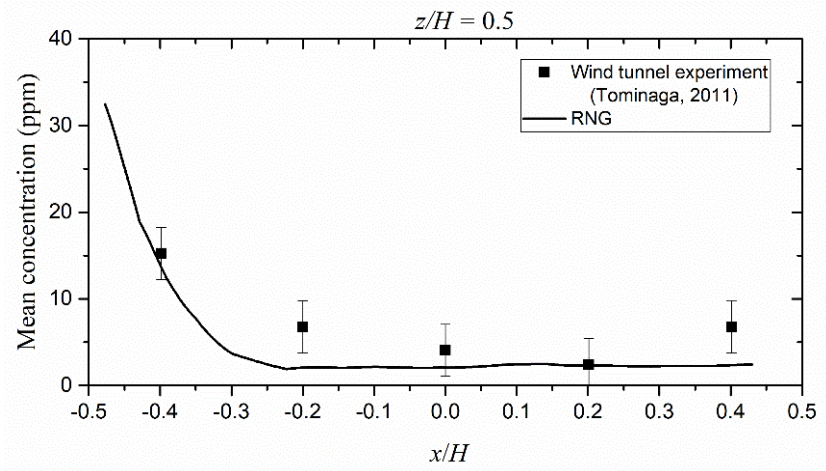




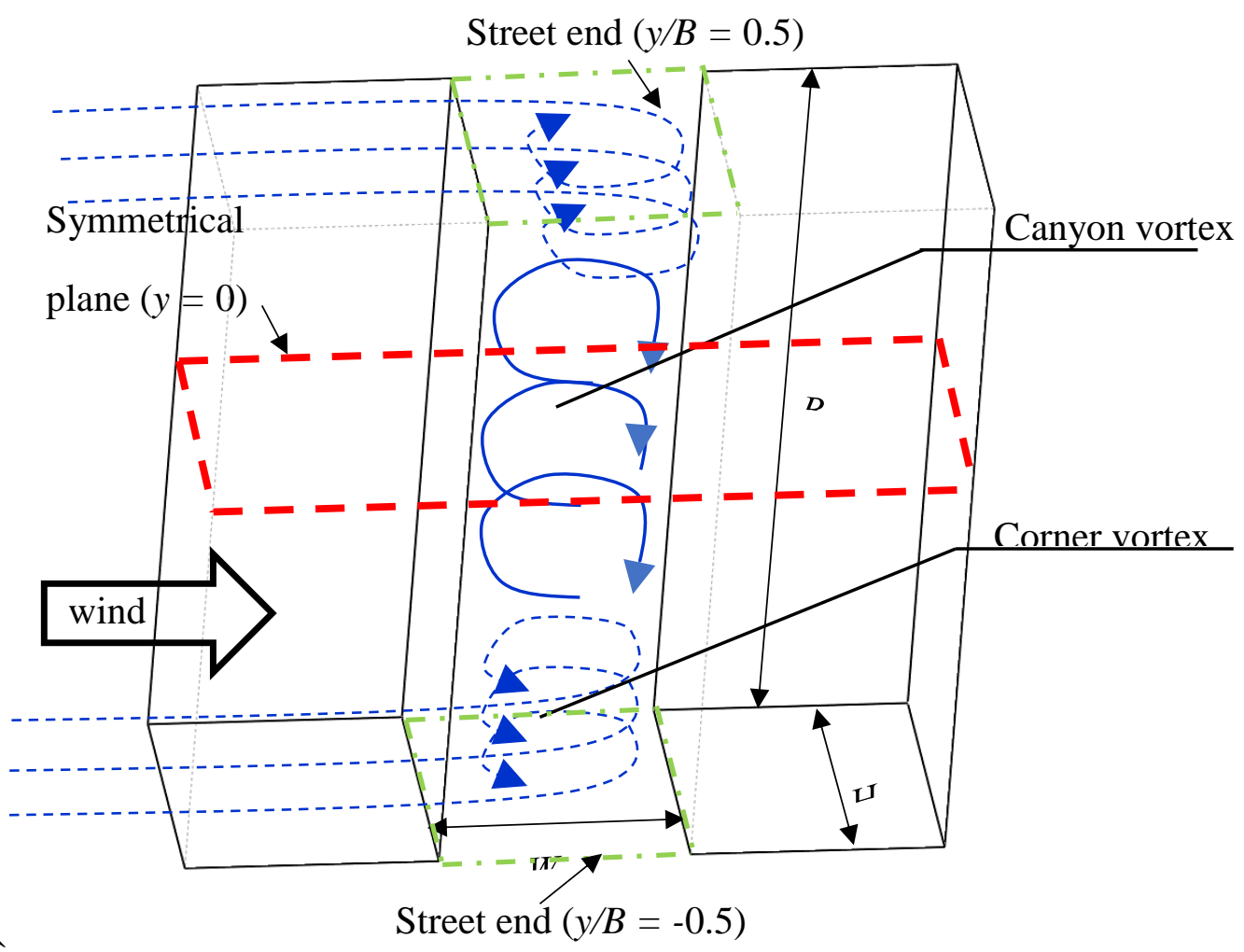

698 Fig. 5. Schematic illustration of the flow pattern within a 3-D street canyon surrounded 699 by urban buildings and subjected to perpendicular approaching wind. The location of 700 street ends and symmetrical planes are presented. The wind blows from the left to the 701 right.

702

703

704

705

706

707

708

709

710 
712

Figure 6

713

714

715

716

717

718

719

720

721
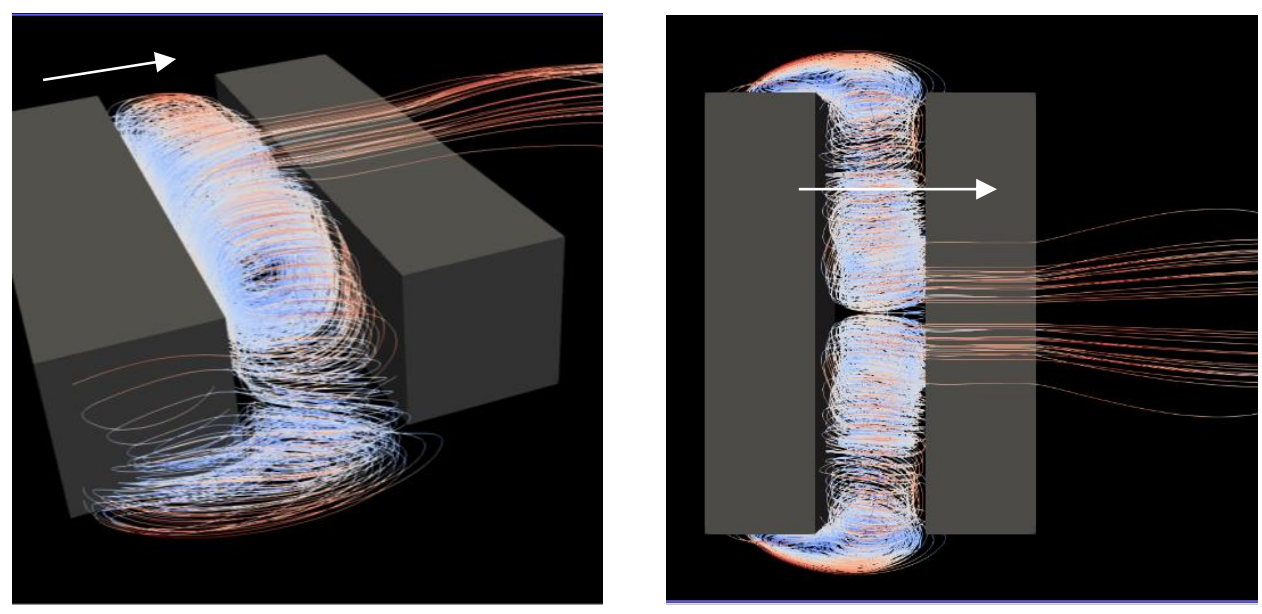

(a)
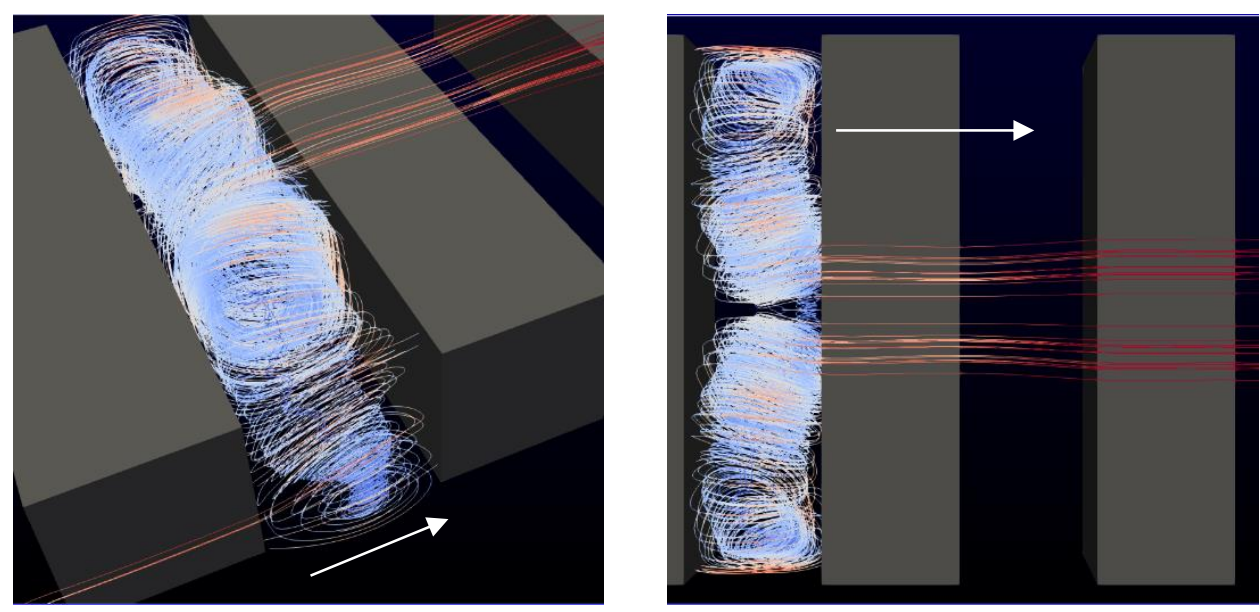

(b)

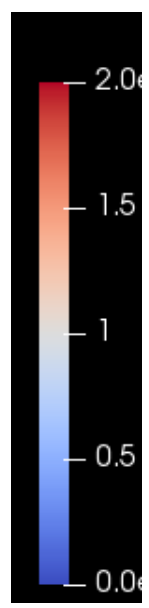

722 Fig. 6. 3-D streamline in street canyons with $(H / W=1.0, B / W=4.0)$ for isolated street

723 canyon (a) and multiple canyons (b). The streamlines are coloured by mean velocity.

724 Streamlines are originated from multiple seed locations on a straight line above the line 725 source $(z / H=0.1)$. The ambient wind blows from the left to the right. 
Figure 7
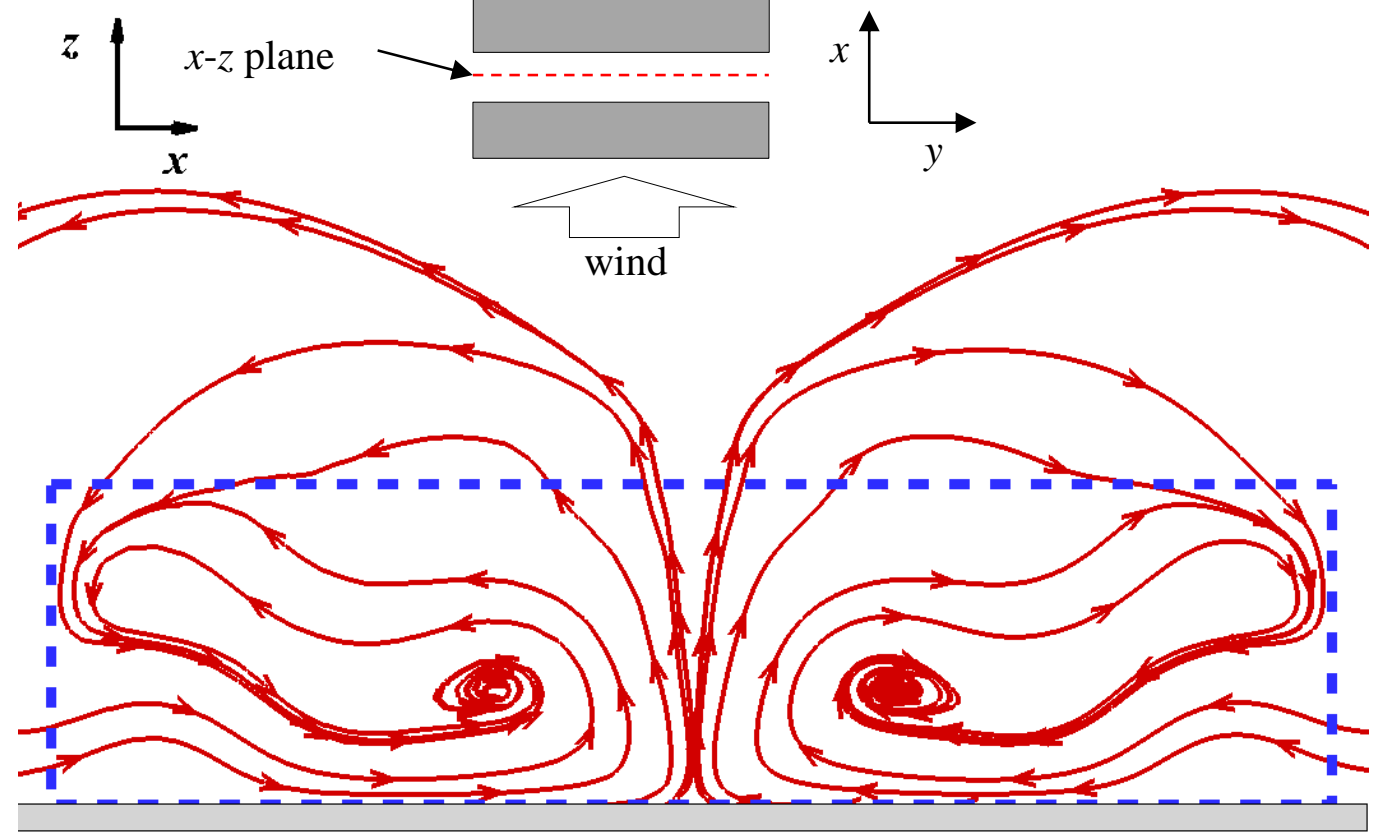

Fig. 7. Filtered streamlines plotted at the vertical plane ( $x-z$ plane, located at the street centreline, shown as red dash) for cases with $H / W=1$ and $B / W=4$. Noted that the $x$ velocity was filtered as zero at that plane to transfer $3 \mathrm{D}$ streamlines into $2 \mathrm{D}$ streamlines. 


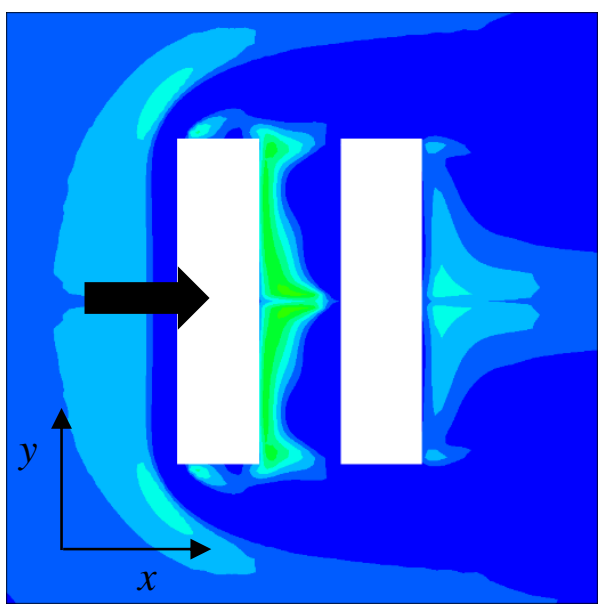

(a) Single canyon $B / H=4, z / H=0.1$

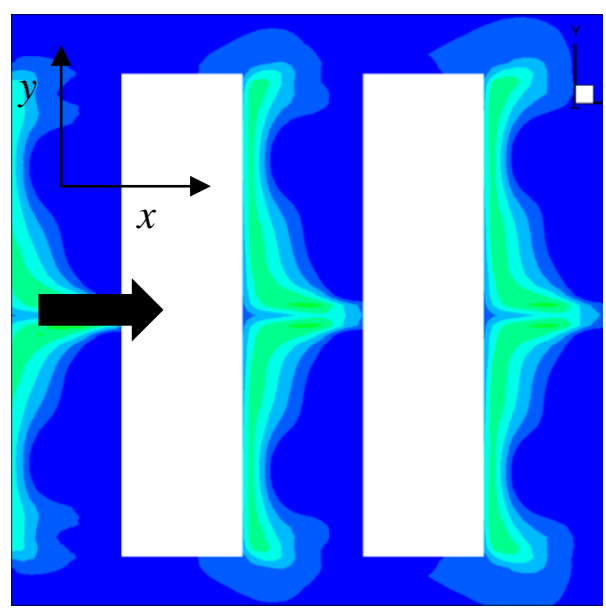

(c) Multiple canyon $B / H=4, z / H=$

0.1

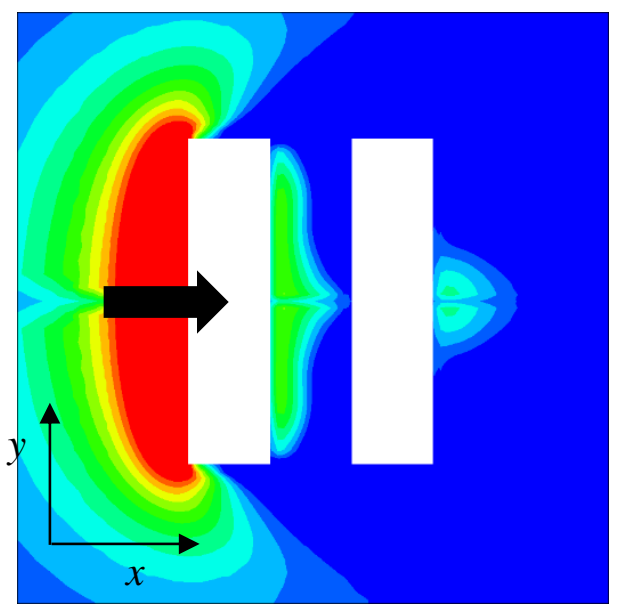

(b) Single canyon $B / H=4, z / H=1.0$

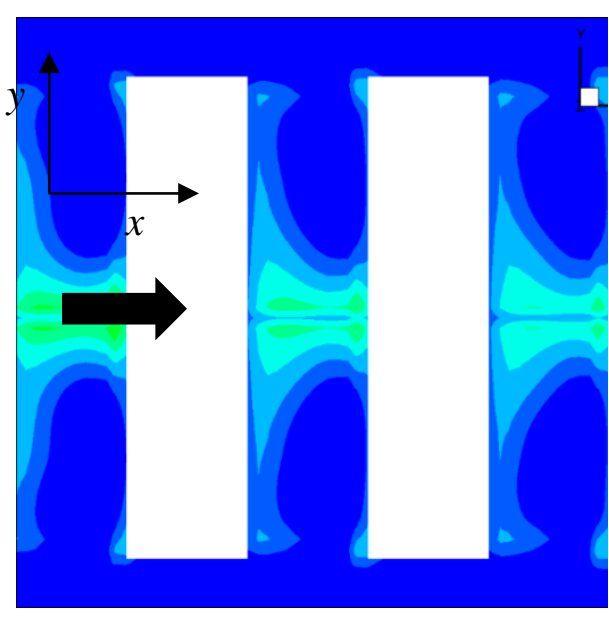

(d) Multiple canyon $B / H=4, z / H=$ 1.0

759 Fig. 8. The normalized mean vertical velocity $w^{*}=w / U_{\text {ref }}$ at two different height of $\mathrm{z}=$ $7600.1 H$ and $1.0 H$ for cases with $H / W=1$ and $B / W=4$. The ambient wind blows from the 761 left to the right.

Figure 9 

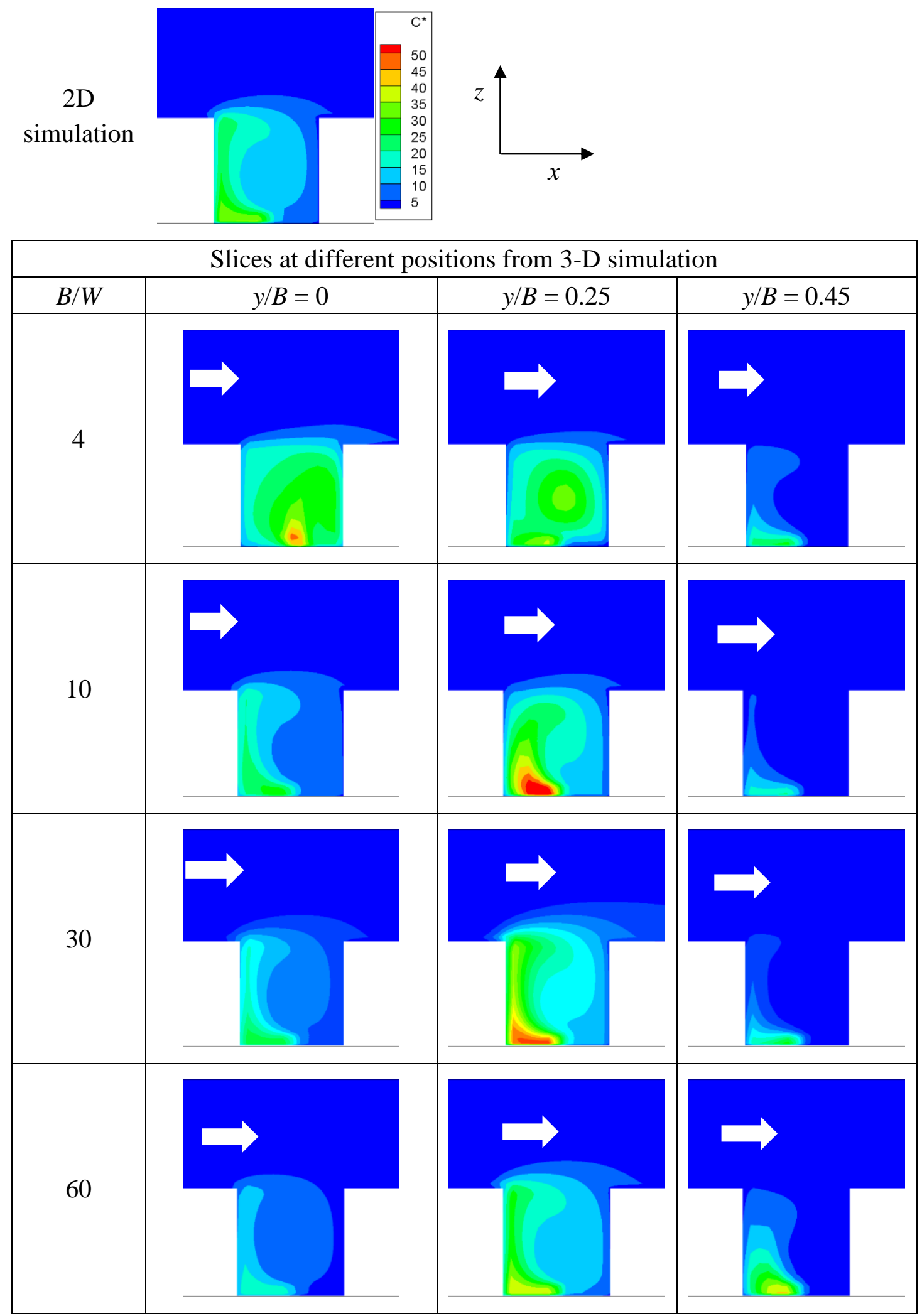

768 Fig. 9. Normalized pollutant concentration at 2-D simulation and $y$-planes for 3-D street 769 canyon with isolated canyon and $H / W=1.0$. The ambient wind blows from the left to the 770 right.

771 Figure 10 
2-D simulation
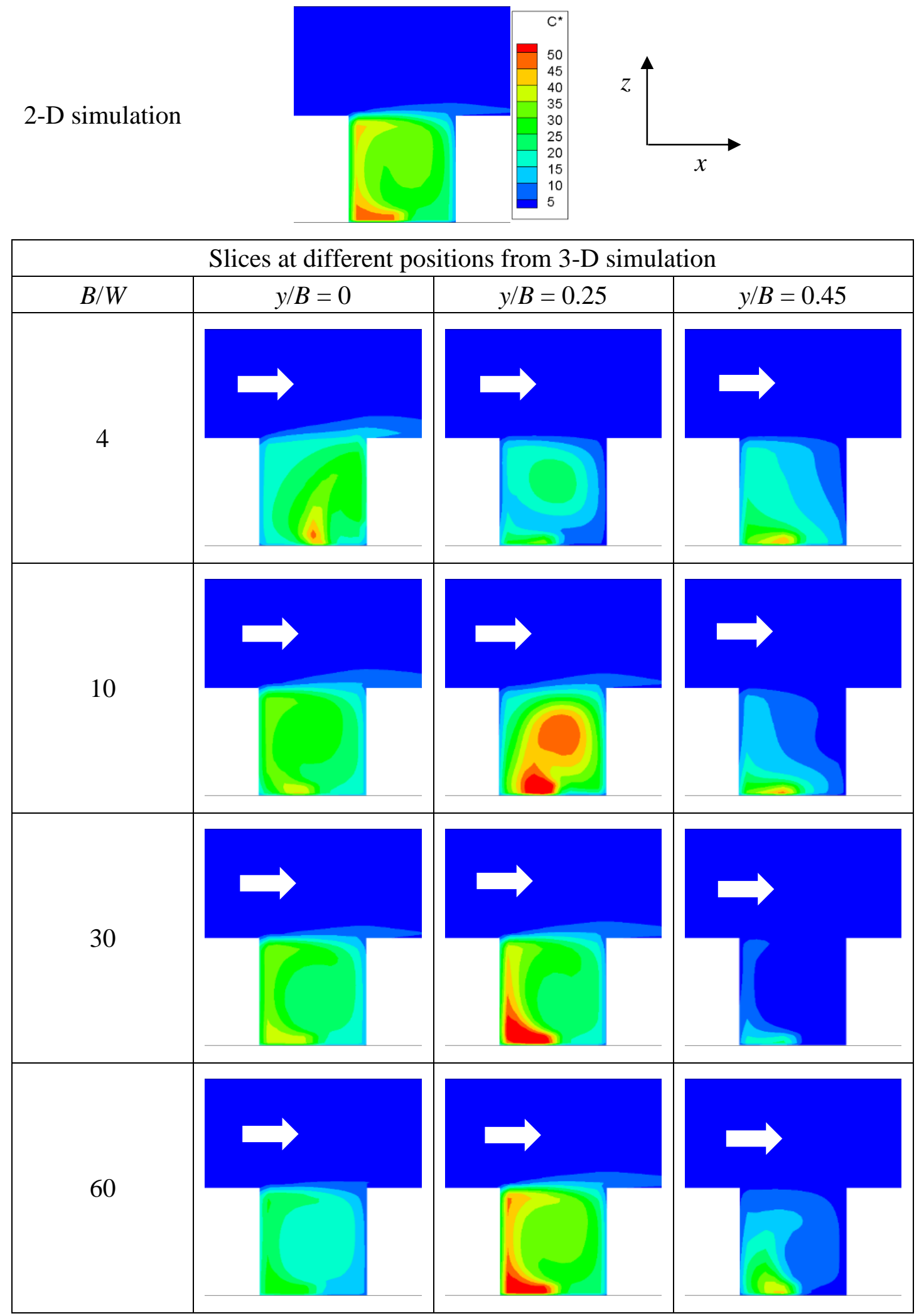

772 Fig. 10. Normalized pollutant concentration at 2-D simulation and $y$-planes for 3-D street 773 canyon with multiple canyon and $H / W=1.0$. The ambient wind blows from the left to the 774 right.

775 Figure 11 


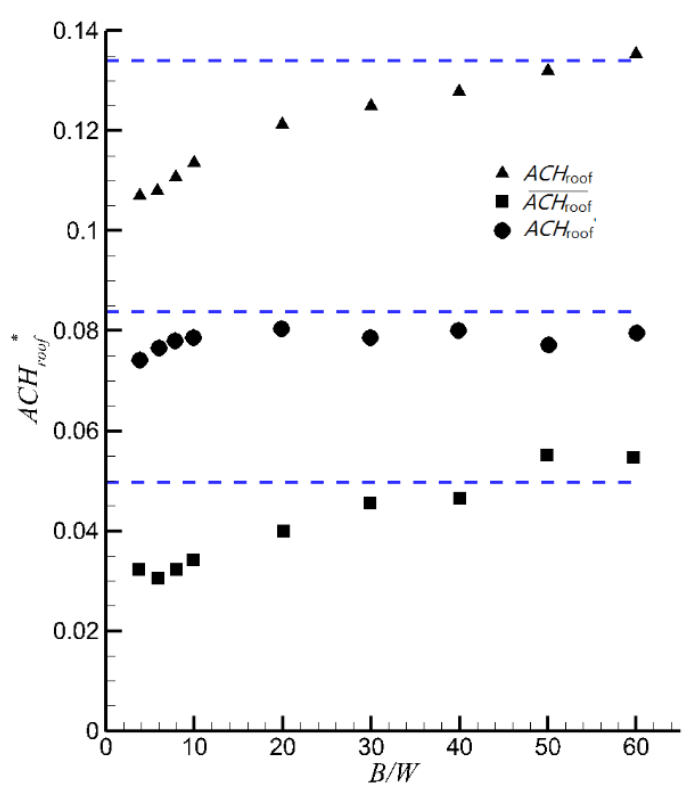

(a) single canyon $(H / W=1)$

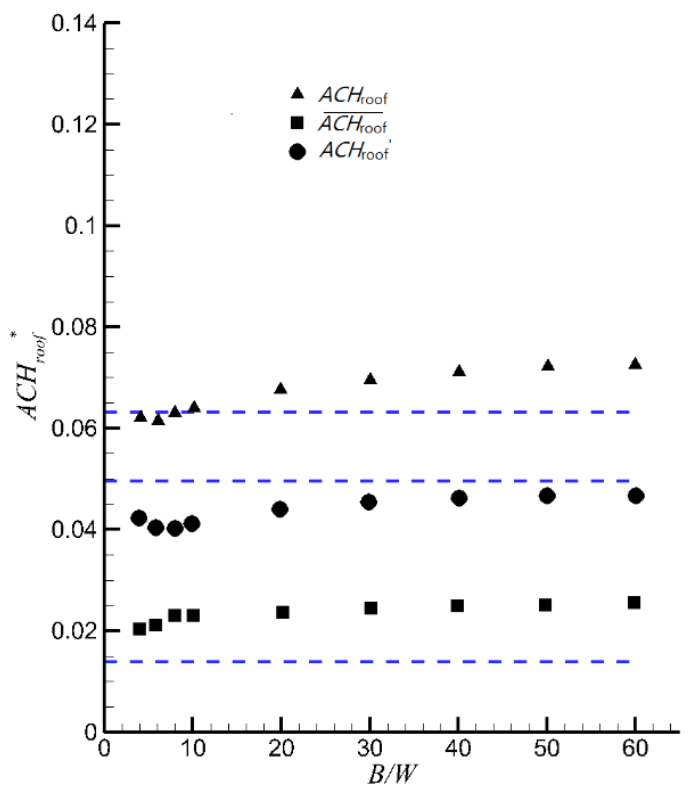

(c) Multiple canyon $(H / W=1)$

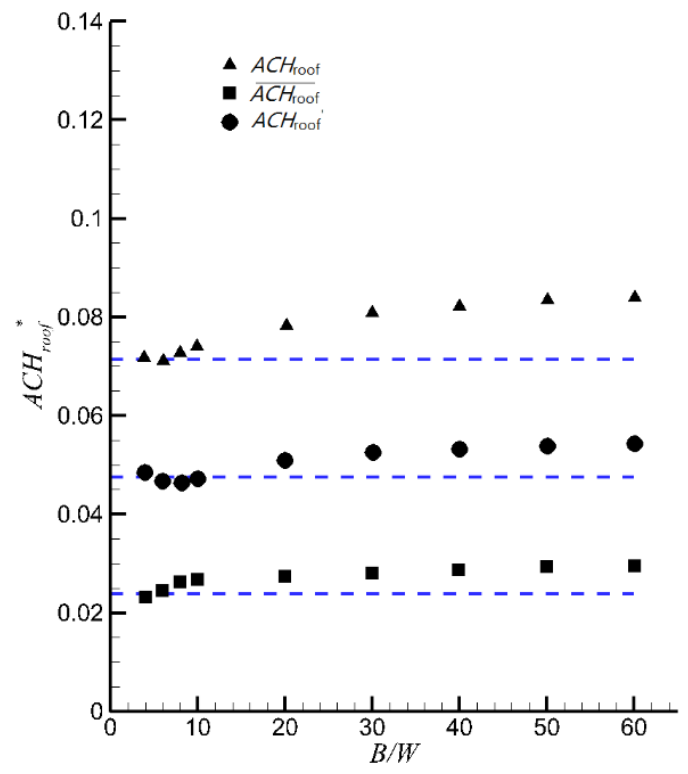

(b) single canyon $(H / W=2)$

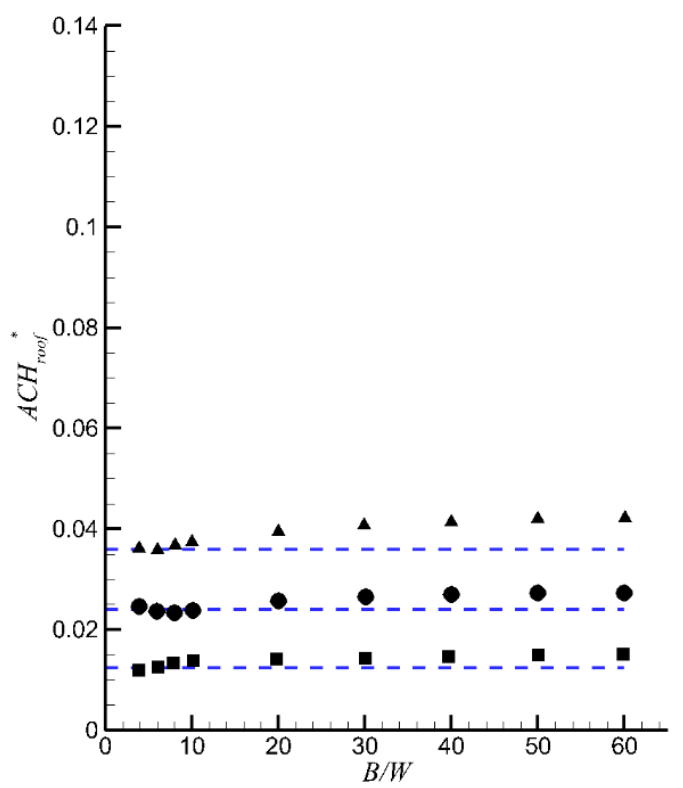

(d) Multiple canyon $(H / W=2)$

777 Fig. 11. Relationship between street length $(B / W)$ and the overall air exchange rate

$\left.778 A C H_{\text {roof }}\right)$, mean exchange rate $\left(\overline{A C H_{\text {roof }}}\right)$ and turbulent exchange rate $\left(A C H_{\text {roof }}^{\prime}\right)$ at the roof.

779 The air exchange rates are normalized as $A C H^{*}\left(=A C H / U_{\text {ref }}\right)$. The results of 2-D

780 simulation are plotted as blue dash lines.

$781 \quad$ Figure 12 


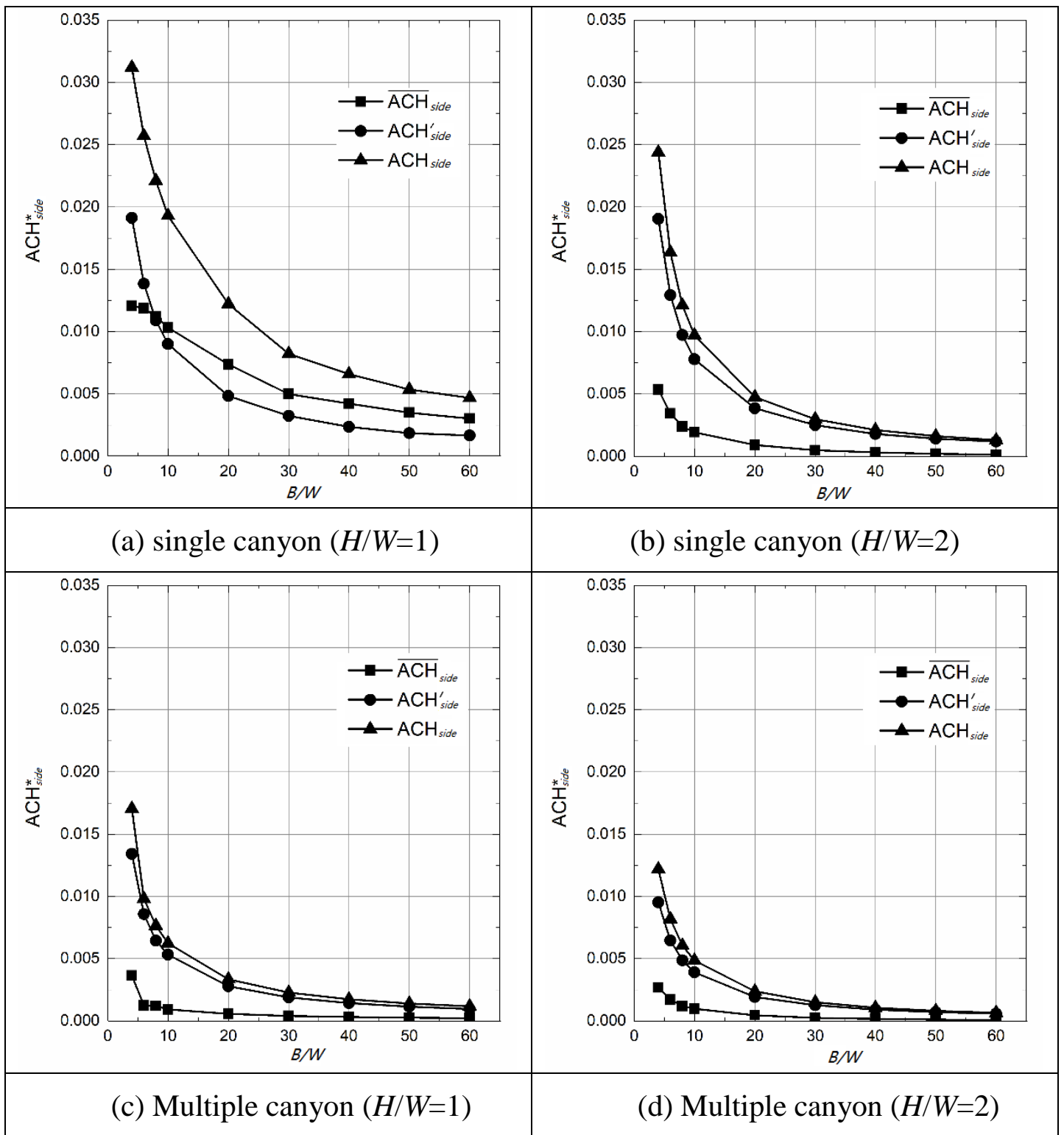

Fig. 12. Relationship between street length $(B / W)$ and the overall air exchange rate ( $\left.A C H_{\text {side }}\right)$, mean exchange rate $\left(\overline{A C H_{\text {side }}}\right)$ and turbulent exchange rate $\left(A C H_{\text {side }}^{\prime}\right)$ at the street ends. The air exchange rates are normalized as $A C H^{*}\left(=A C H / U_{\text {ref }}\right)$. The results of 2-D simulation are plotted as blue dash lines. 


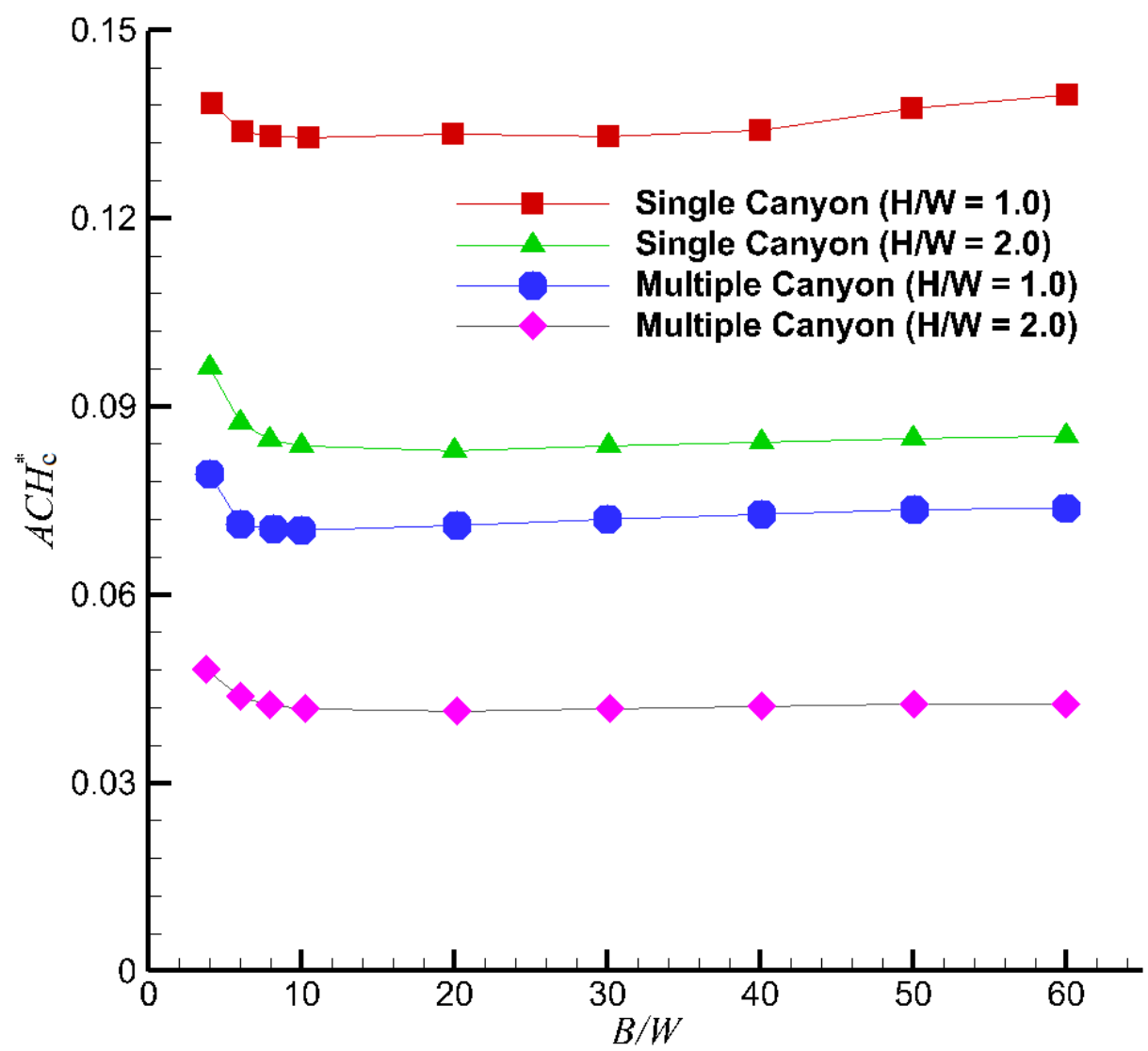

799

800 Fig. 13. The overall air exchange rate $\left(A C H_{\mathrm{c}}{ }^{*}\right)$ of the whole street canyon against $B / W(B$

801 the street length, $W$ the street width).

802

803

804

805

806

807

808

809

810

811 
$812 \quad$ Figure 14

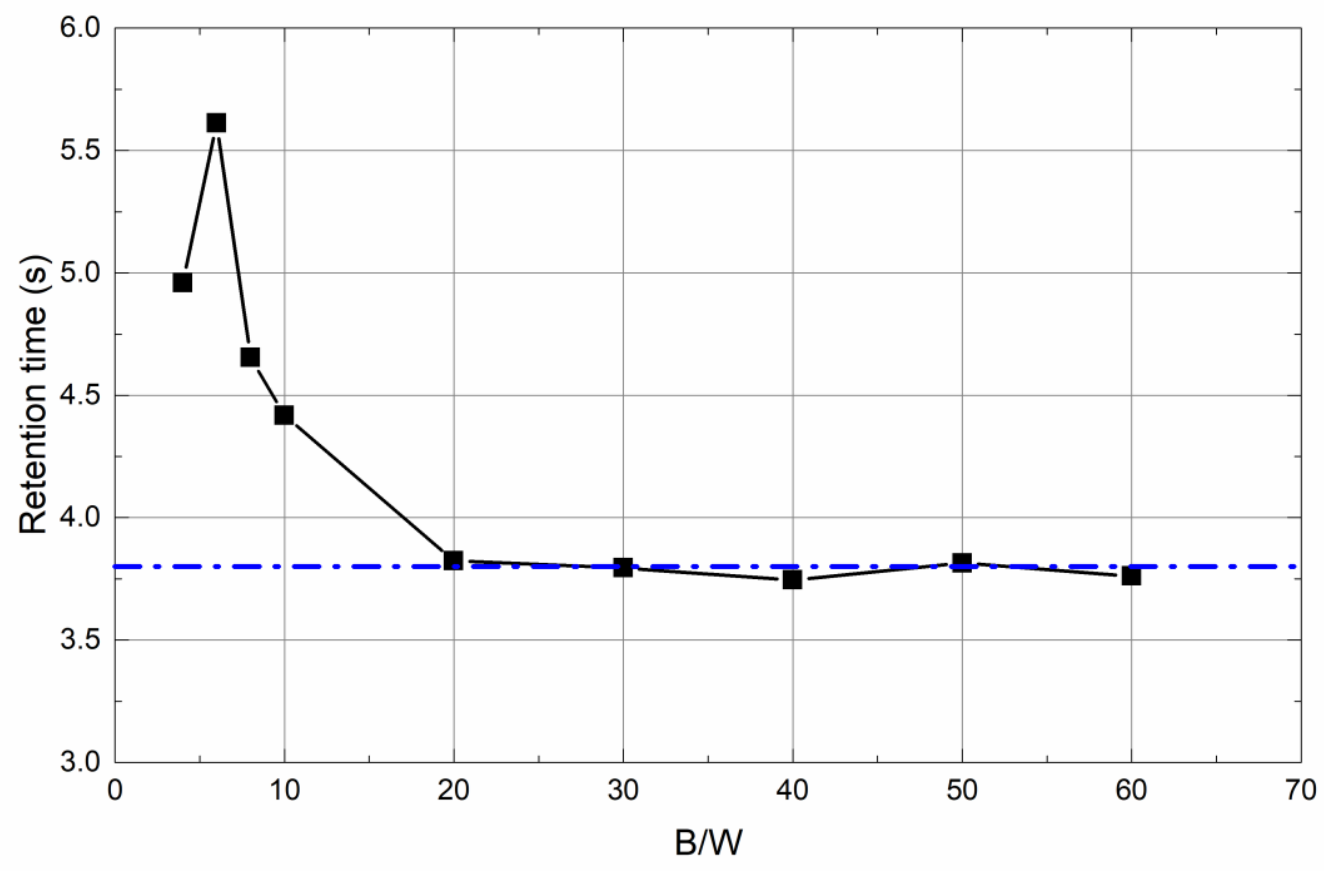

813

814

(a) Isolated canyon $(H / W=1.0)$

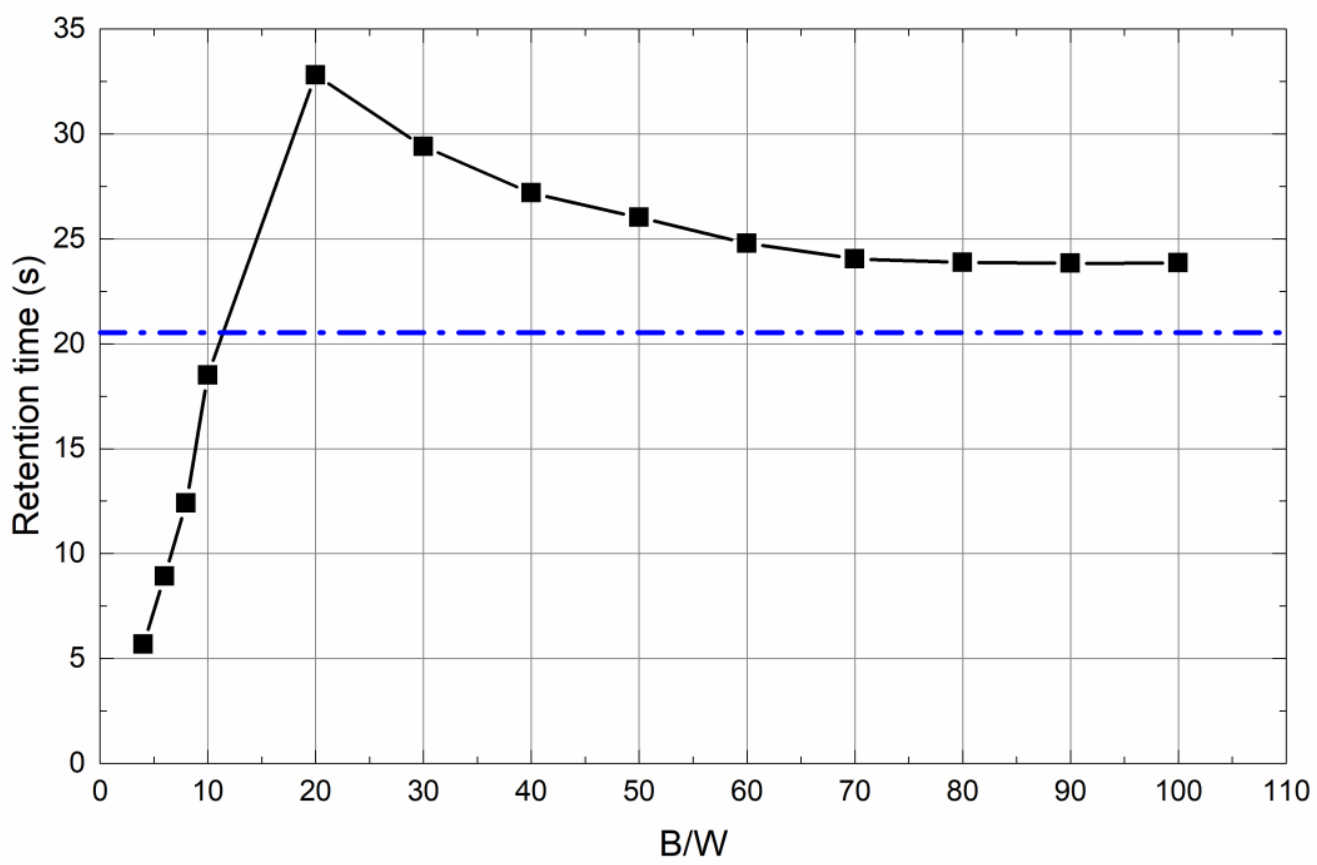

815

(b) Isolated canyon $(H / W=2.0)$

816 


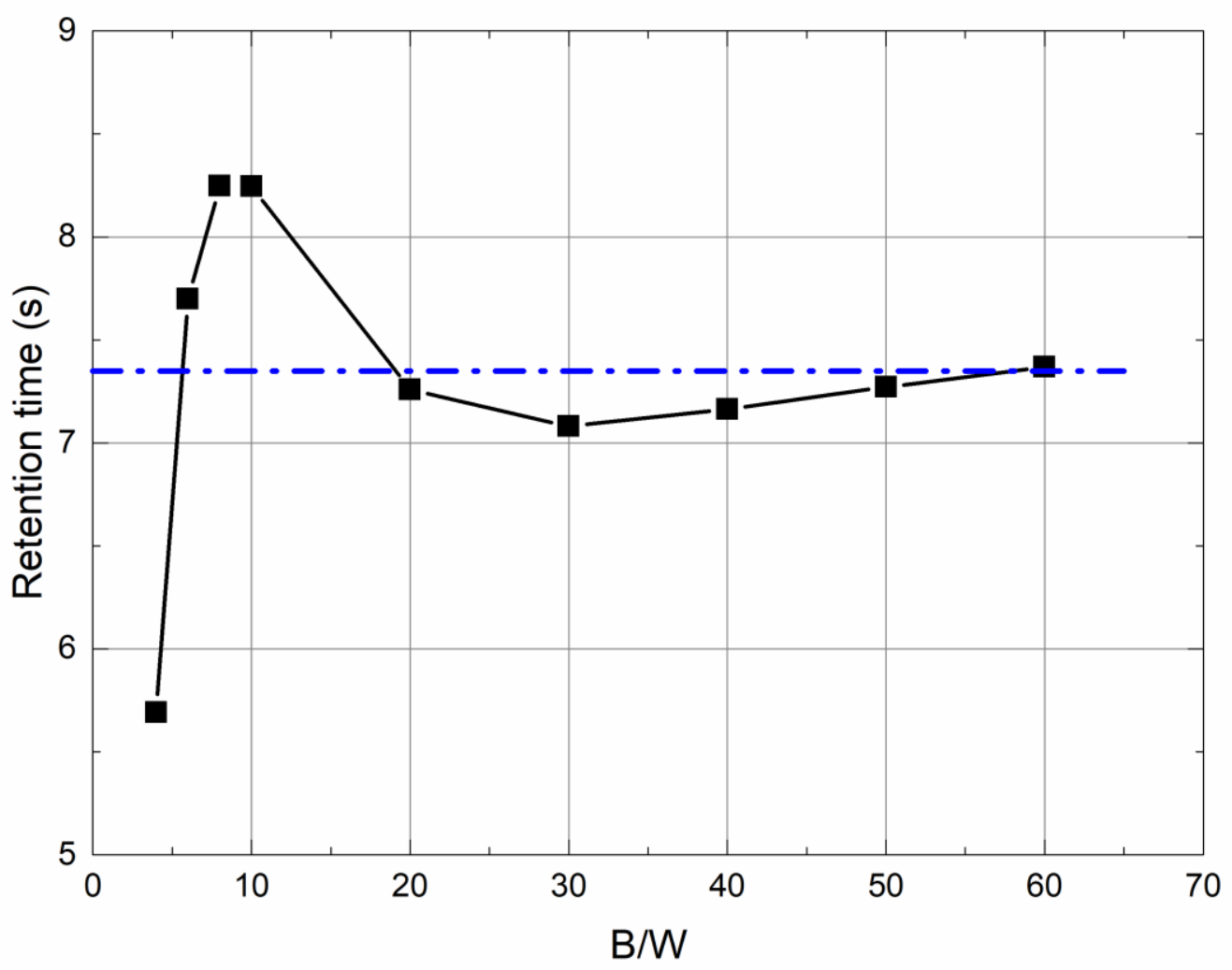

817

818

(c) Multiple canyon $(H / W=1.0)$

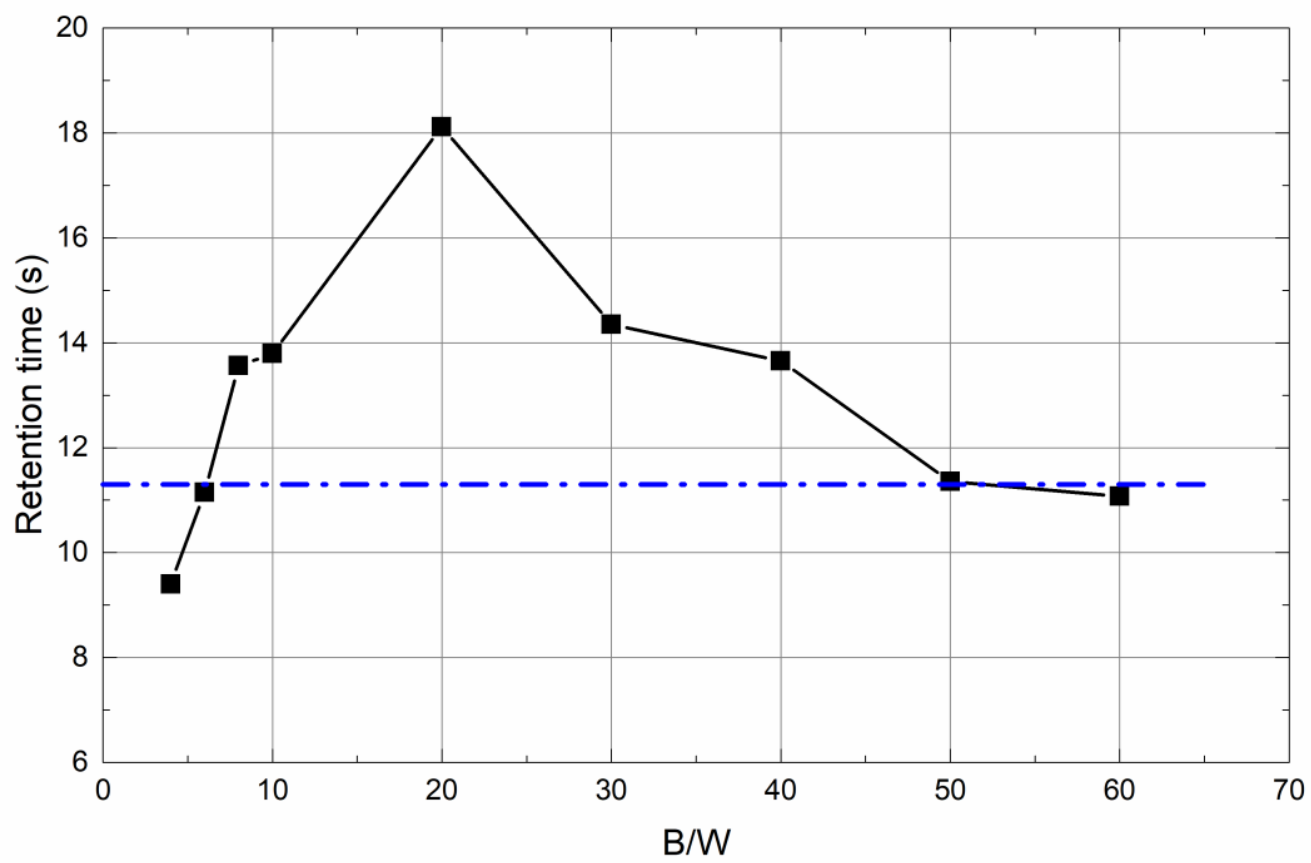

819

(d) Multiple canyon $(H / W=2.0)$

820

821

822

Fig. 14. Canyon retention time $\tau_{\mathrm{c}}$ against street length $B / W$. 


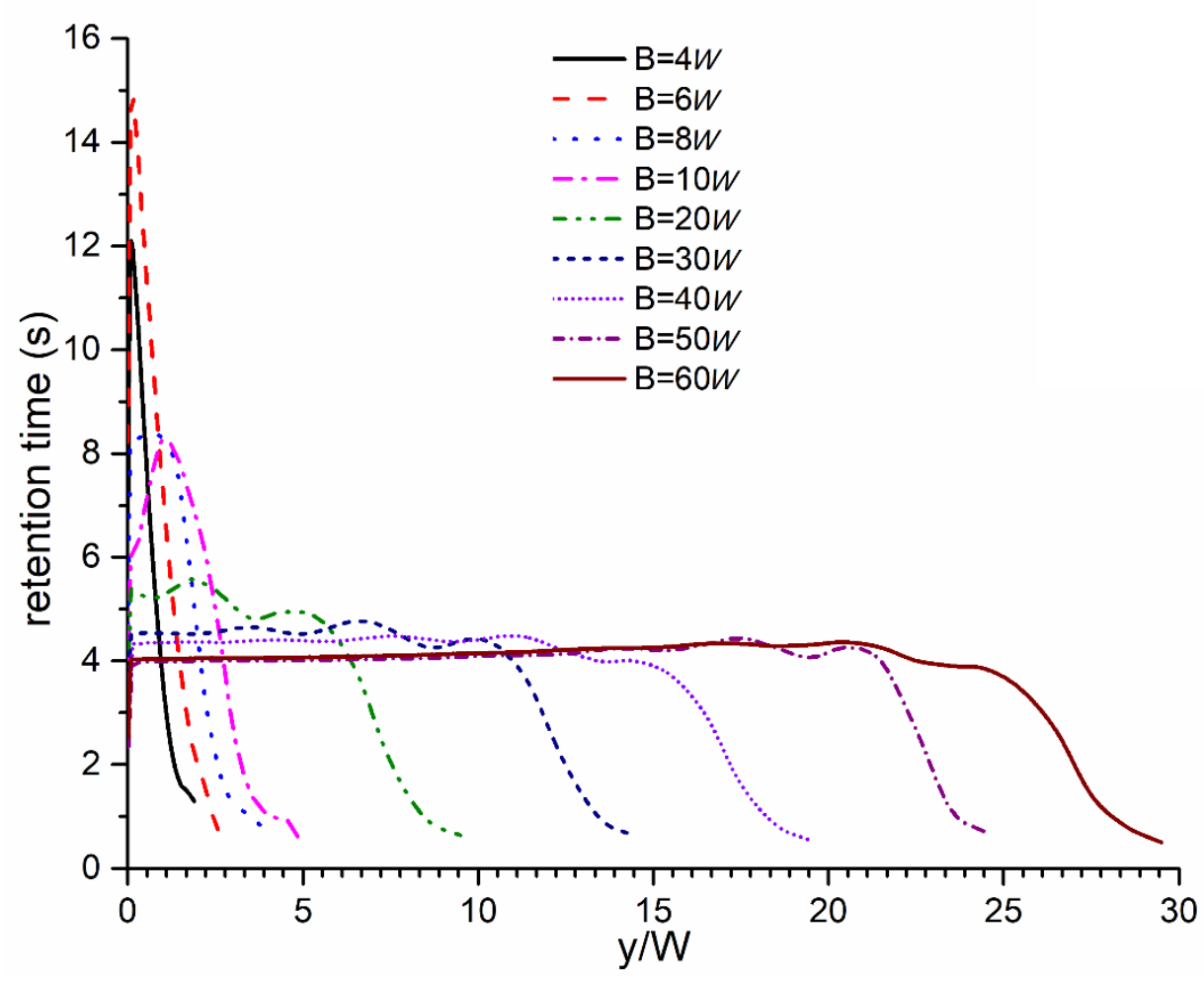

827

(a) Isolated canyon $(H / W=1.0)$

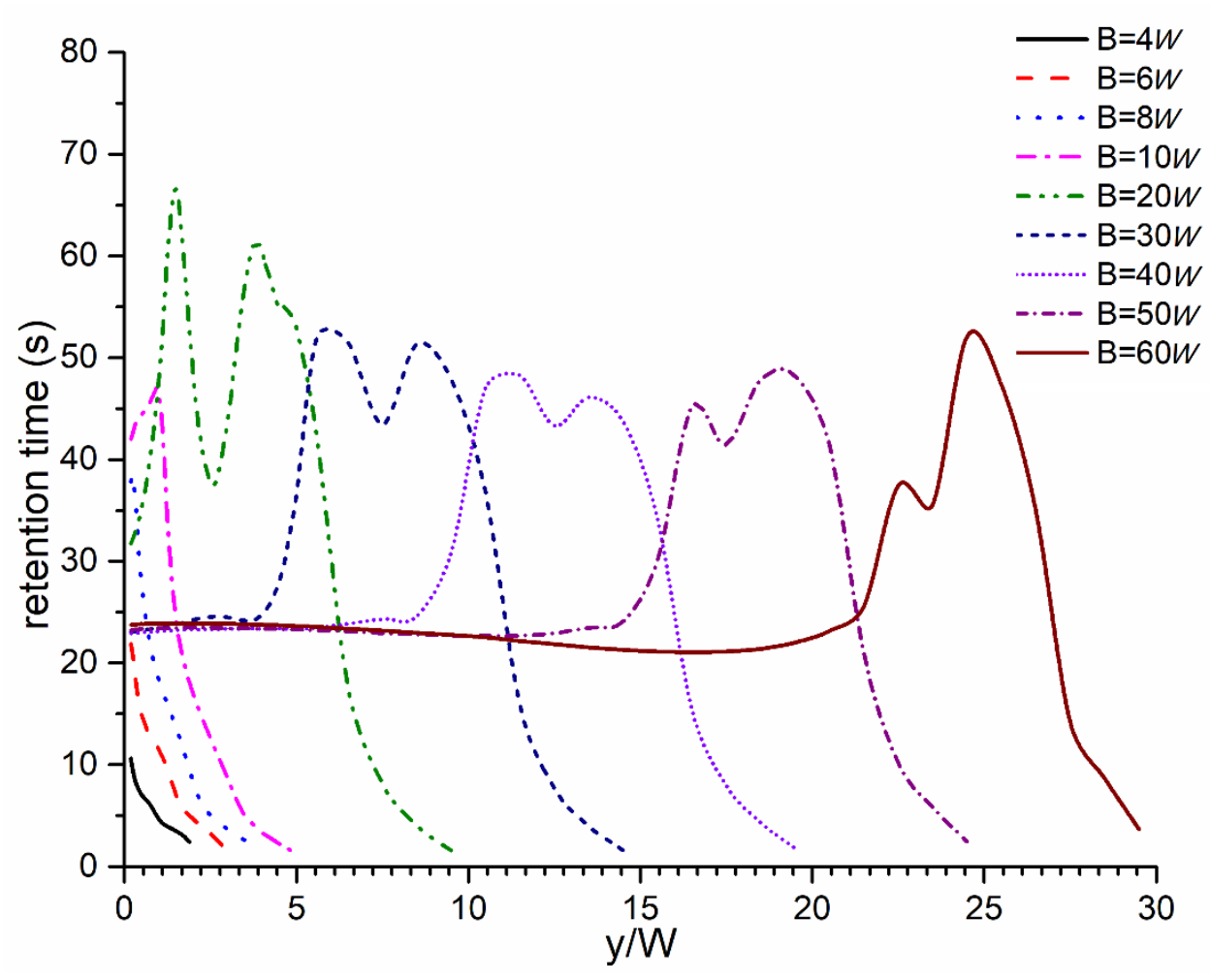

(b) Isolated canyon $(H / W=2.0)$ 


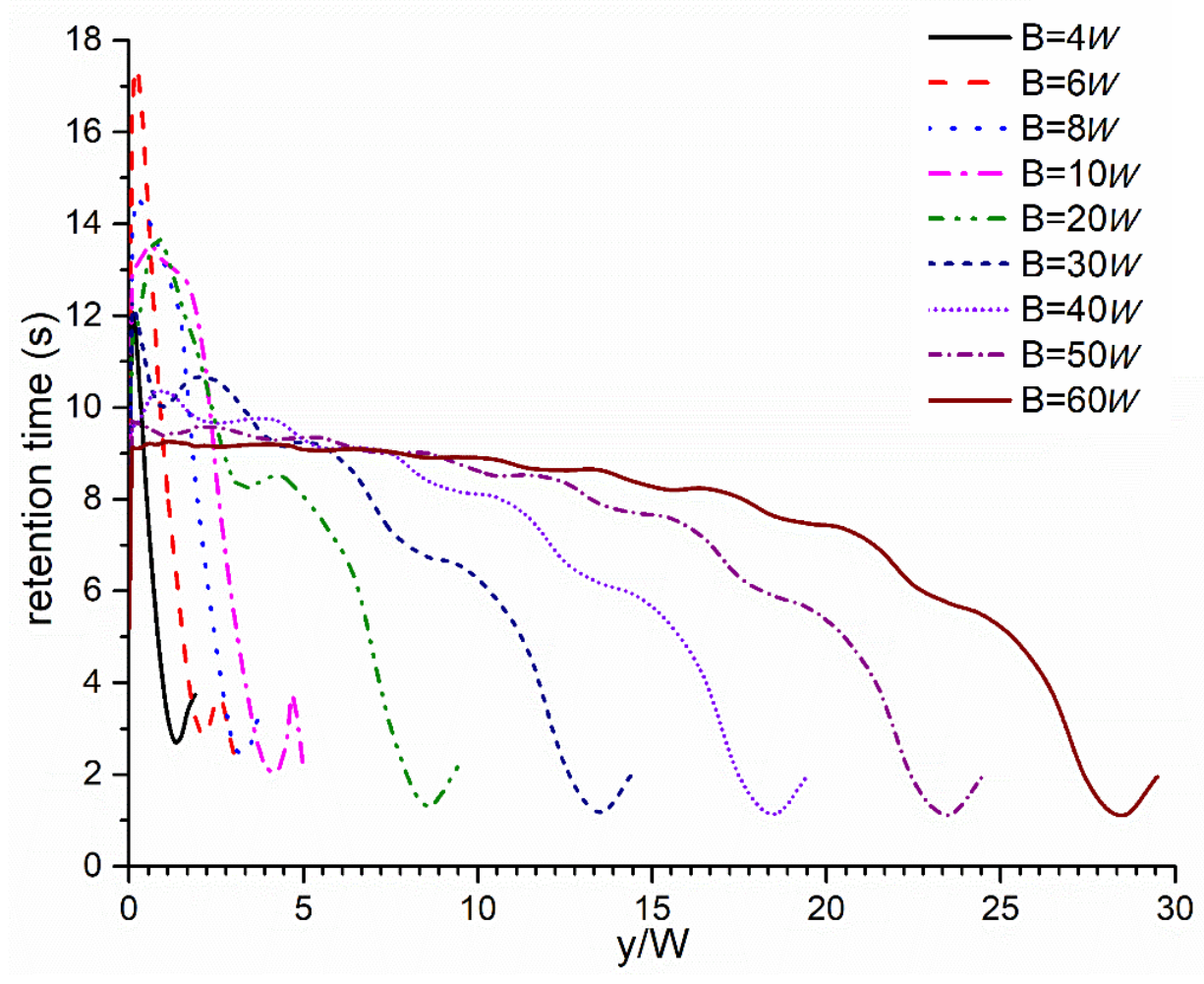

830

(c) Multiple canyon $(H / W=1.0)$

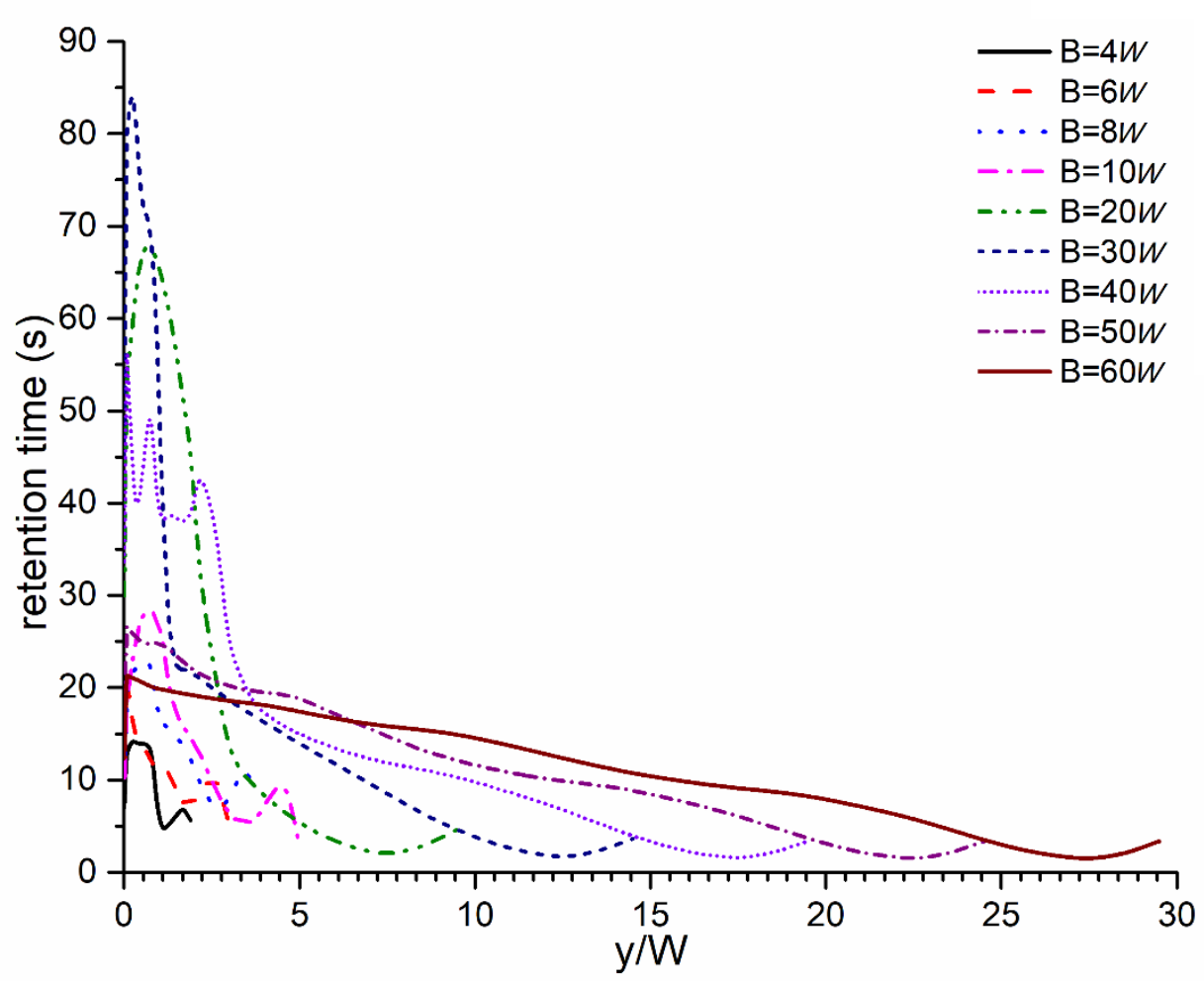

(d) Multiple canyon $(H / W=2.0)$

834 Fig. 15. Distribution of averaged retention time along street direction ( $y$-direction). 